\title{
Refining projected multidecadal hydroclimate uncertainty in East-Central Europe using CMIP5 and single-model large ensemble simulations
}

\author{
Dániel Topál ${ }^{1,2}$ (D) István Gábor Hatvani ${ }^{1}$ (D) Zoltán Kern $^{1}$ (D) \\ Received: 11 February 2019 / Accepted: 20 August 2020 / Published online: 7 September 2020 \\ (C) The Author(s) 2020
}

\begin{abstract}
Future hydroclimate projections of global climate models for East-Central Europe diverge to a great extent, thus, constrain adaptation strategies. To reach a more comprehensive understanding of this regional spread in model projections, we make use of the CMIP5 multi-model ensemble and six single-model initial condition large ensemble (SMILE) simulations to separate the effects of model structural differences and internal variability, respectively, on future hydroclimate projection uncertainty. To account for model uncertainty, we rank 32 CMIP5 models based on their predictive skill in reproducing multidecadal past hydroclimate variability. Specifically, we compare historical model simulations to long instrumental and reanalysis surface temperature and precipitation records. The top 3-ranked models - that best reproduce regional past multidecadal temperature and precipitation variability - show reduced spread in their projected future precipitation variability indicating less dry summer and wetter winter conditions in part at odds with previous expectations for Central Europe. Furthermore, not only does the regionally best performing CMIP5 models belong to the previously identified group of models with more realistic landatmosphere interactions, their future summer precipitation projections also emerge from the range of six SMILEs' future simulations. This suggests an important role for land-atmosphere coupling in regulating hydroclimate uncertainty on top of internal variability in the upcoming decades. Our results help refine the relative contribution of structural differences between models in affecting future hydroclimate uncertainty in the presence of irreducible internal variability in East-Central Europe.
\end{abstract}

Keywords GCM $\cdot$ Ranking $\cdot$ Model evaluation $\cdot$ Large ensemble $\cdot$ Uncertainty $\cdot$ Hydroclimate

\section{Introduction}

Human-induced changes in the climate system are already detectable on daily-to-decadal timescales (Santer et al. 2018; Sippel et al. 2020). Changing weather patterns (Rosenzweig et al. 2008), expanding dryland regions

Electronic supplementary material The online version of this article (https://doi.org/10.1007/s00704-020-03361-7) contains supplementary material, which is available to authorized users.

Dániel Topál

topal@ucsb.edu

1 Institute for Geological and Geochemical Research, Research Centre for Astronomy and Earth Sciences, MTA Centre for Excellence, Budapest H-1112, Hungary

2 Earth Research Institute, University of California, Santa Barbara, Santa Barbara, CA, USA
(Huang et al. 2016) and the dramatic reduction of Arctic sea ice (Screen and Simmonds 2010; Dai et al. 2019), are just a few from the vast set of climatic changes attributed to rising greenhouse gas concentrations. Besides global impacts, alterations in regional scale climate patterns are also observable. Specifically, East-Central Europe is believed to become more susceptible to the incidence of climate extremities in response to increased radiative forcing (Seneviratne et al. 2006; Bartholy and Pongrácz 2007; Beniston et al. 2007; Hirschi et al. 2010). Nevertheless, internal variability - an inherent feature of chaotic climate dynamics (Zeng et al. 1993) - is also known to have substantially contributed to, or masked the effects of anthropogenically forced climate change (Ding et al. 2014, 2019; Swart et al. 2015; Baxter et al. 2019; Topál et al. 2020), although conclusions on how internal variability might behave under future warming scenarios are still controversial (Deser et al. 2012, 2020; Dai et al. 2015; Haszpra and Herein 2019; Haszpra et al. 2020a,b). 
Fig. 1 Location of the study area on an orography map. The purple and blue dashed lines represent the HISTALP Northeast (NE) and Southeast (SE) regions. The primary target area is selected as the rectangle overlapping the $\mathrm{NE}$ and $\mathrm{SE}$ regions, i.e., $43^{\circ} \mathrm{N}-50^{\circ}$ $\mathrm{N} ; 13^{\circ} \mathrm{E}-19.5^{\circ} \mathrm{E}$. The black rectangle represents the Central Europe (CEU) domain (extended target area) used to evaluate CMIP5 models against the NOAA twentieth century reanalysis

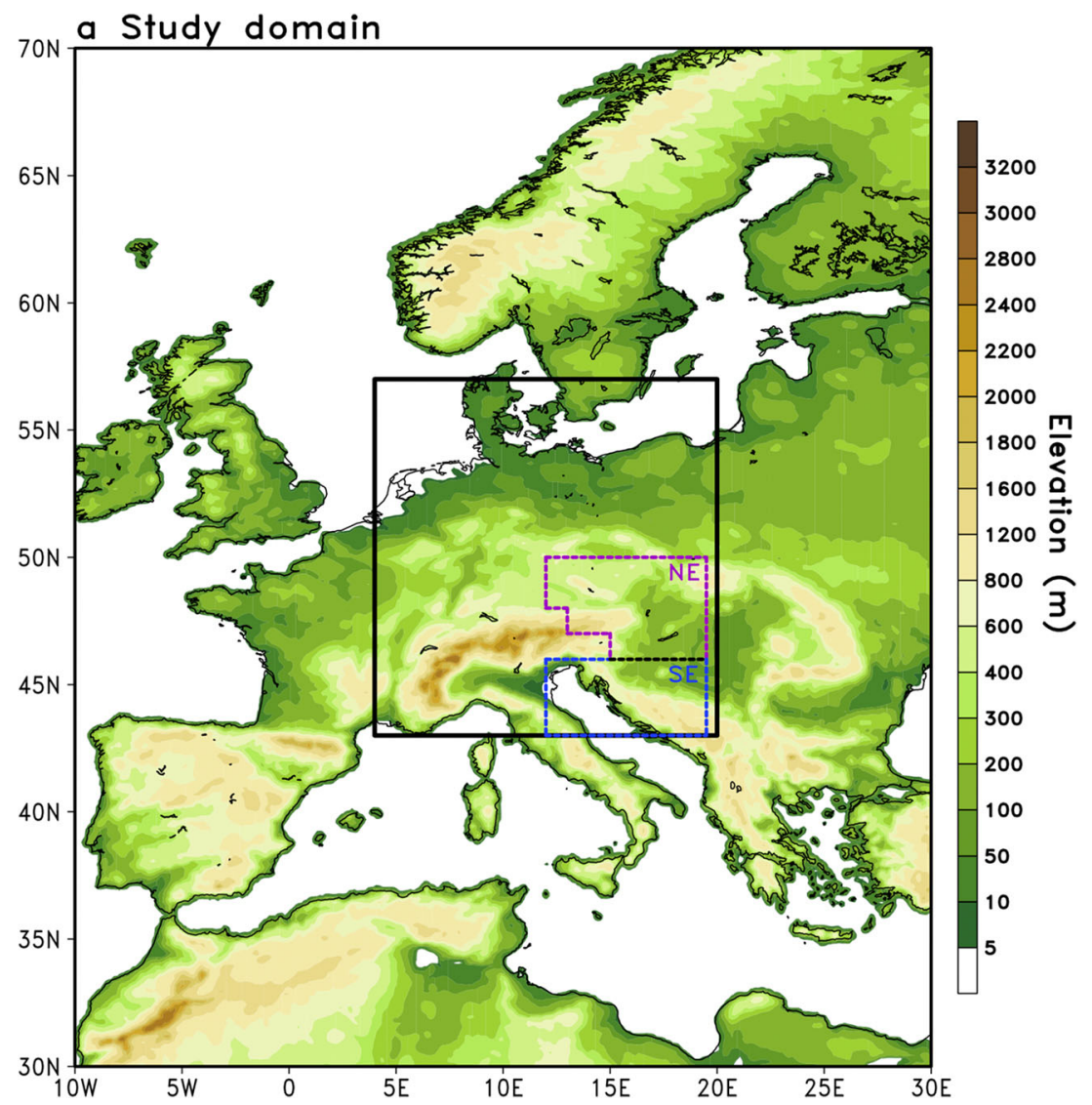

Global climate models (GCMs) are elaborate tools for simulating past, present, and future climatic and environmental changes on various timescales; however, any projection is riddled with three commonly mentioned uncertainties: scenario uncertainty, model uncertainty, and internal variability (Stainforth et al. 2007; Knutti 2008; Hawkins and Sutton 2009). Thus, coordinated modeling experiments have launched to address these uncertainties. The Coupled Model Intercomparison Project Phase 5 (CMIP5, Taylor et al. 2012b) collected a number of GCMs with differing model physics, manifested chiefly in the different parametrization schemes applied in them. This dissimilarity tends to lead to structural differences between the models and thought to account for most of the uncertainty regarding their performance (Knutti 2008; Knutti and Sedláček 2013; Harrison et al. 2015), while the choice of the external forcing scenario plays a subtle role (Reichler and Kim 2008). One practice to acknowledge GCM limitations is to use a multi-model ensemble (Suh et al. 2012; L'Heureux et al. 2017) and consider each GCM with equal weight. However, to abandon "model democracy" and weight or give preference to certain models in a multi-model ensemble based on performance, ranking was also proposed (Knutti 2010; Merrifield et al. 2019). The latter has proved effective in constraining model uncertainty (Knutti et al. 2017) and is of particular importance when studying climatic variables (e.g., precipitation) whose future projections show large spread between different models (Garfinkel et al. 2020).

Action taken in this direction introduced the application of diverse model ranking methodologies, ranging from studies using correlation, root-mean-square error, and variance ratio (Boer and Lambert 2001; Gleckler et al. 2008) to the application of prediction indices (Murphy et al. 2004) or to those taking a Bayesian approach (Min and Hense 2006). In addition, the concern of interdependency of CMIP models (Sanderson et al. 2015) has been re-evaluated recently (Olson et al. 2019). Regarding the target area of model evaluation Garfinkel et al. (2020) studied the sources of CMIP5 intermodel spread in precipitation changes globally, however, ample analyses are targeted at more regional areas, e.g., the North-Atlantic (Perez et al. 2014), parts of Europe (Coppola et al. 2010; Pieczka et al. 2017), Africa (Brands et al. 2013; Dyer et al. 2019; Yapo et al. 2020), South-America (Lovino et al. 2018), or Asia (Ahmed et al. 2019).

Policy and management actions taken in response to the environmental hazards linked to climatic change, especially the consideration of the societal and agricultural impacts of extreme climate events, are limited by the uncertainties around GCM performance and internal variability too (Knutti and Sedláček 2013). There is growing body of evidence that the regional accuracy of GCM simulations is critical for regional 
Fig. 2 Time series of standardized (relative to 19712000 mean) seasonal mean precipitation projections of 31 CMIP5 models for 2021-2085 (31-year moving averaged) for the primary target area $\left(43^{\circ} \mathrm{N}-50^{\circ}\right.$ $\left.\mathrm{N} ; 13^{\circ} \mathrm{E}-19.5^{\circ} \mathrm{E}\right)$ a for summer (June-July-August: JJA) and b for winter (December-JanuaryFebruary: DJF)
31 CMIP5 PR JJA 2021-2085
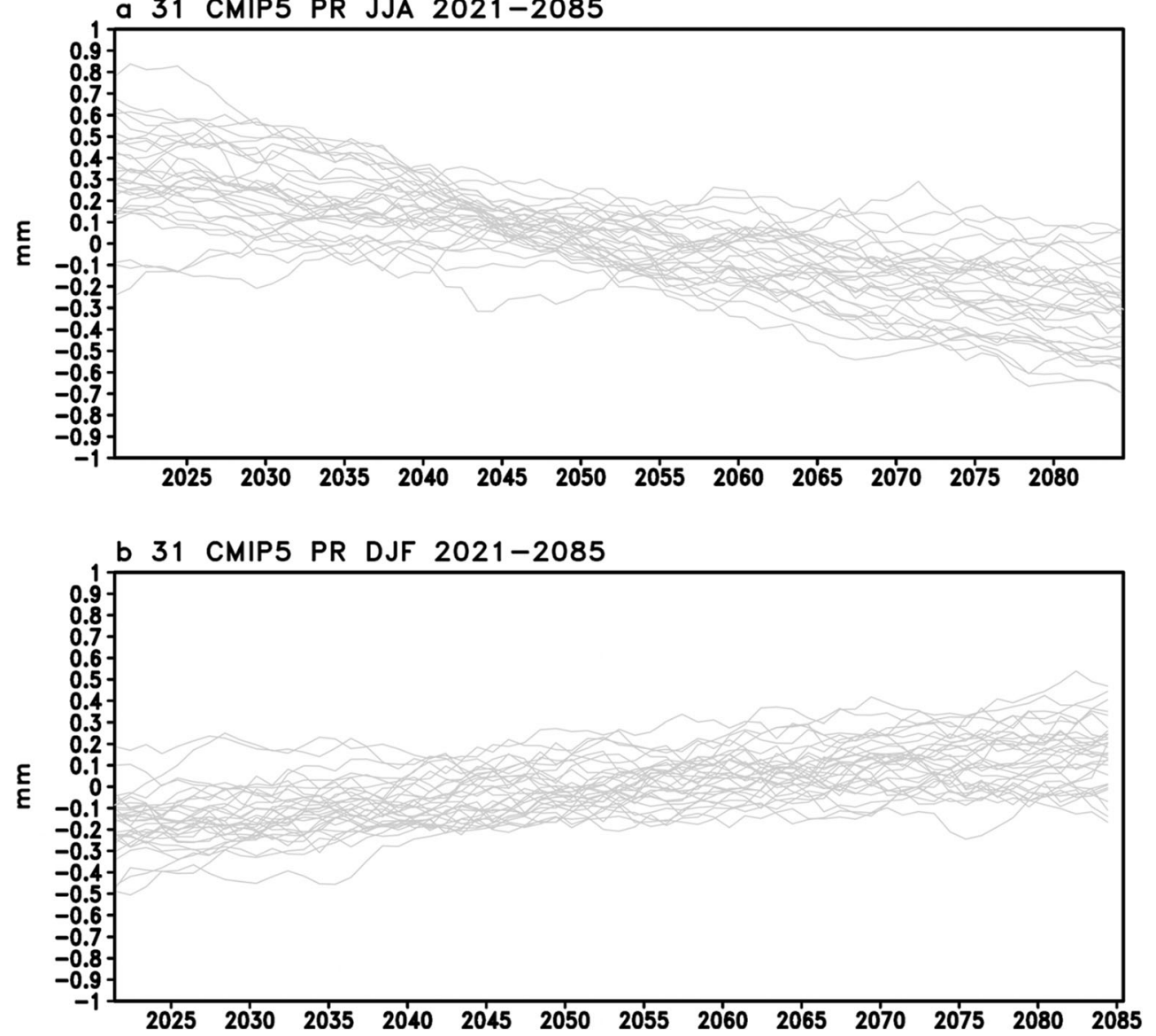

climate model (RCM) projections. An RCM nested in a GCM that lacks the skillful representation of the observed largescale climatic modes and circulation (i.e., boundary conditions for the RCM) cannot be expected to generate realistic results (Gautam and Mascaro 2018; Verfaillie et al. 2019). Despite a model's agreement with current or more distant past observations does not always guarantee credibility to its future projections, the fact that it is based on physical principles supports the idea of using past observations as constraints in hope of selecting models with more reliable future projections (Reichler and Kim 2008; Sheffield et al. 2013; Sillmann et al. 2013; Wang et al. 2014; Barnes and Polvani 2015). Consequently, boosting the robustness of regional GCM projections via the rigorous evaluation of their uncertainties is crucial, especially for those that drive RCMs in the MEDCORDEX project (Ruti et al. 2016).

Several studies indicate that structural differences, namely the land-atmosphere feedback strength, between models can indeed be a source of uncertainty in future precipitation projections (e.g., Schwingshackl et al. 2018). However, the exact physical mechanisms such as how changes in soil moisture affect precipitation or temperature extremes remain uncertain (Boberg and Christensen 2012; Taylor et al. 2012a; Berg et al. 2016). Recently Vogel et al. (2018)—based on CMIP5 models with more realistic land-atmosphere couplingsconcluded a future reduction in summer drying and warm extremes in Central Europe in line with a study by Selten et al. (2020). Nevertheless, how internal variability may influence the selection of best performing models and thus the uncertainty in future precipitation projections remains unaddressed.

Internal variability can be considered the parallel existence of numerous climate states at a given time (Lorenz 1963). It is an inherent feature of the climate system driven by chaotic dynamics (Bódai and Tél 2012; Drótos et al. 2015, 2016, 2017; Herein et al. 2016, 2017). In single-model initial condition large ensemble (SMILE) simulations, unlike the CMIP5 multi-model ensemble, the same model is run several times with perturbations in the initial condition. The single runsdiffering in their initial conditions exclusively - constitute the members of the ensemble whose spread is related to internal variability with the ensemble mean reflecting the forced component.

In this paper, we aim to complement the inconclusive literature on East-Central European future precipitation projections and assess CMIP5 historical model performance based on long instrumental records from the HISTALP database (Auer et al. 2007) and the National Oceanic and 
Table 132 CMIP5

models used in the study (excluding NorESM1-M for the future timeframe). Expansions/definitions of the models are available online (https:// www.ametsoc.org/ PubsAcronymList)

\begin{tabular}{l} 
CMIP5 model \\
\hline ACCESS1-0 \\
ACCESS1-3 \\
CanESM2 \\
CMCC-CESM \\
CMCC-CM \\
CMCC-CS \\
CNRM-CM5 \\
CSIRO-Mk3.6 \\
FGOALS-s2 \\
GFDL-CM3 \\
GFDL-ESM2G \\
GFDL-ESM2M \\
GISS-E2-CC \\
GISS-E2-H \\
GISS-E2-R-CC \\
GISS-E2-R \\
HadGEM2-AO \\
HadGEM2-CC \\
HadGEM2-ES \\
INM-CM4 \\
IPSL-CM5A-LR \\
IPSL-CM5A-MR \\
IPSL-CM5B-LR \\
MIROC-ESM-CHEM \\
MIROC-ESM \\
MIROC5 \\
MPI-ESM-LR \\
MPI-ESM-MR \\
MRI-CGCM3 \\
MRI-ESM1 \\
NorESM1-M \\
NorESM1-ME \\
\end{tabular}

Atmospheric Administration (NOAA) twentieth century reanalysis (Compo et al. 2011; Slivinski et al. 2019) for 18612005 and compare our constrained model ensemble's future precipitation projections to six SMILEs (Deser et al. 2020).
Fig. 3 Surface temperature (TS: red crosses) and precipitation (PR: blue circles) seasonal ranks (uppermost panel), NSE (middle panel), and RMSE (lower panel) for the historical era (1861-2005) across 32 CMIP5 climate models (listed below the $\mathrm{x}$-axis) a for summer (JuneJuly-August: JJA) and b for winter (December-January-February: DJF)

Within the CMIP5 multi-model ensemble, we cannot estimate the relative role for internal variability and model structural differences in influencing the spread of future precipitation projections since, for example, land-atmosphere feedbacks appear with different precision in the 32 CMIP5 models (Cheruy et al. 2014). However, with the inclusion of SMILEs, new opportunities open: we can explore the range of future precipitation projections solely due to internal variability (per model) and thus place CMIP5 model structural differences in the context of internal variability when assessing future hydroclimate uncertainty.

We identify three CMIP5 models with outstanding performance in simulating both regional past hydroclimate variability and land-atmosphere feedbacks (Seneviratne et al. 2013; Vogel et al. 2018), which unanimously indicate significantly less dry future summer conditions relative to the spread of CMIP5 and six SMILE simulations. This emphasizes the role for land-atmosphere coupling in regulating future summer hydroclimate uncertainty and a possible limitation affecting the state-of-the-art SMILE simulations that requires future work to disentangle. Our paper provides new insights into how those models that show better skills in reproducing observed climate variability can help refine future hydroclimate uncertainty in the presence of internal variability and advocates new efforts dedicated to improving model performance in simulating land-atmosphere feedbacks in Central Europe.

\section{Data and methods}

\subsection{Study area description}

The primary target area consists of the northeast (NE) and southeast (SE) subregions of the Greater Alpine Region (43 ${ }^{\circ}$ $\mathrm{N}-50^{\circ} \mathrm{N} ; 13^{\circ} \mathrm{E}-19.5^{\circ} \mathrm{E}$; Fig. 1), which have been delineated

Table 2 Large ensemble simulations used in the study

\begin{tabular}{llllll}
\hline Modeling center & Model version & Abbreviation & Number of members & Time period & Reference \\
\hline CCCma & CanESM2 & CanESM-LE & 50 & $2006-2080$ & Kirchmeier-Young et al. (2017) \\
CSIRO & MK3.6 & CSIRO-LE & 30 & $2006-2080$ & Jeffrey et al. (2013) \\
GFDL & ESM2M & GFDL_ESM2M-LE & 30 & $2006-2080$ & Rodgers et al. (2015) \\
MPI & MPI-ESM-LR & MPI-GE & 100 & $1850-2080$ & Maher et al. (2019) \\
NCAR & CESM1 & CESM-LE & 40 & $2006-2080$ & Kay et al. (2015) \\
SMHI/KNMI & EC-EARTH & EC_EARTH-LE & 16 & $1850-2080$ & Hazeleger et al. (2010) \\
\hline
\end{tabular}


a TS \& PR seasonal rank/NSE/RMSE 1861-2005 JJA
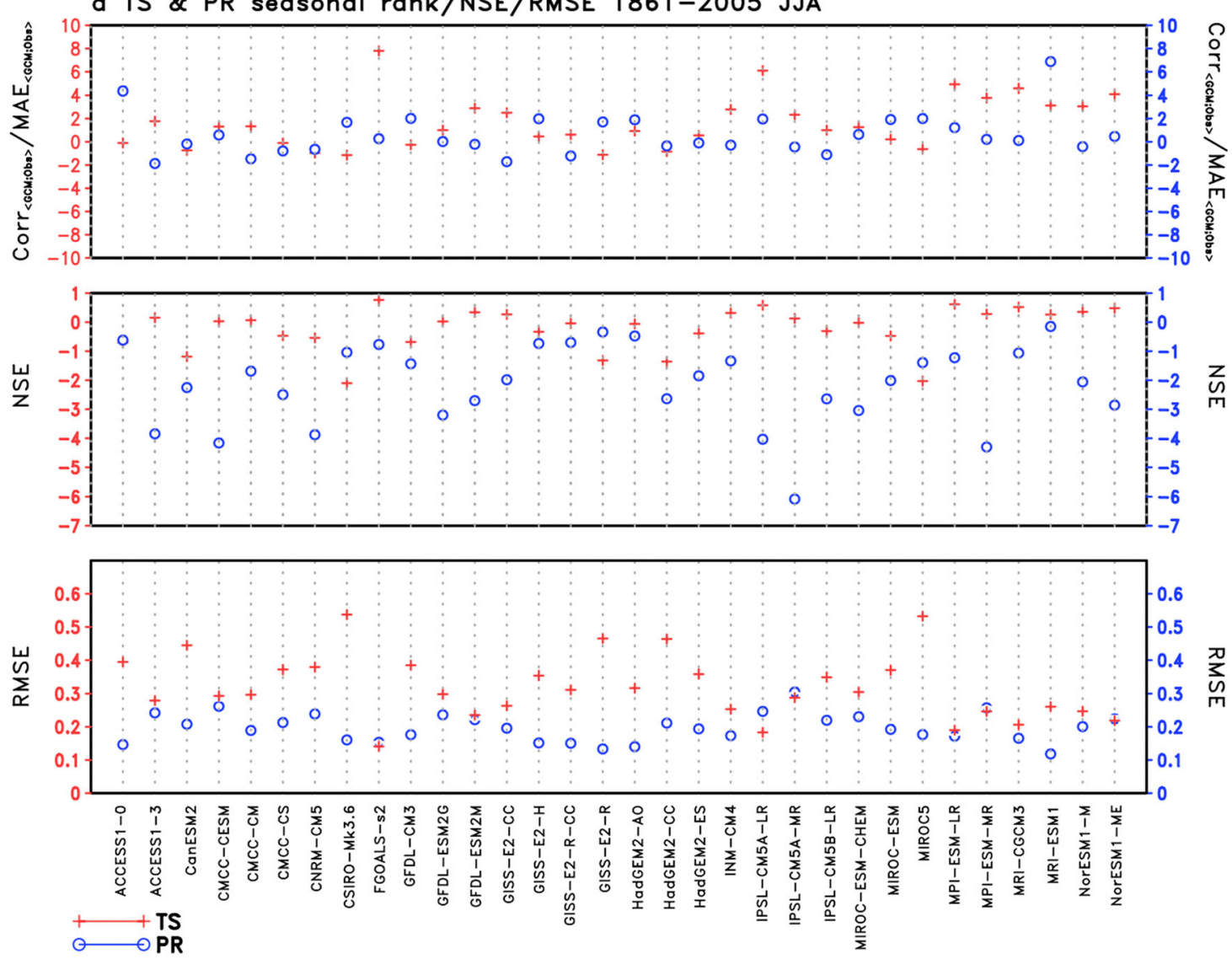

b TS \& PR seasonal rank/NSE/RMSE 1861-2005 DJF
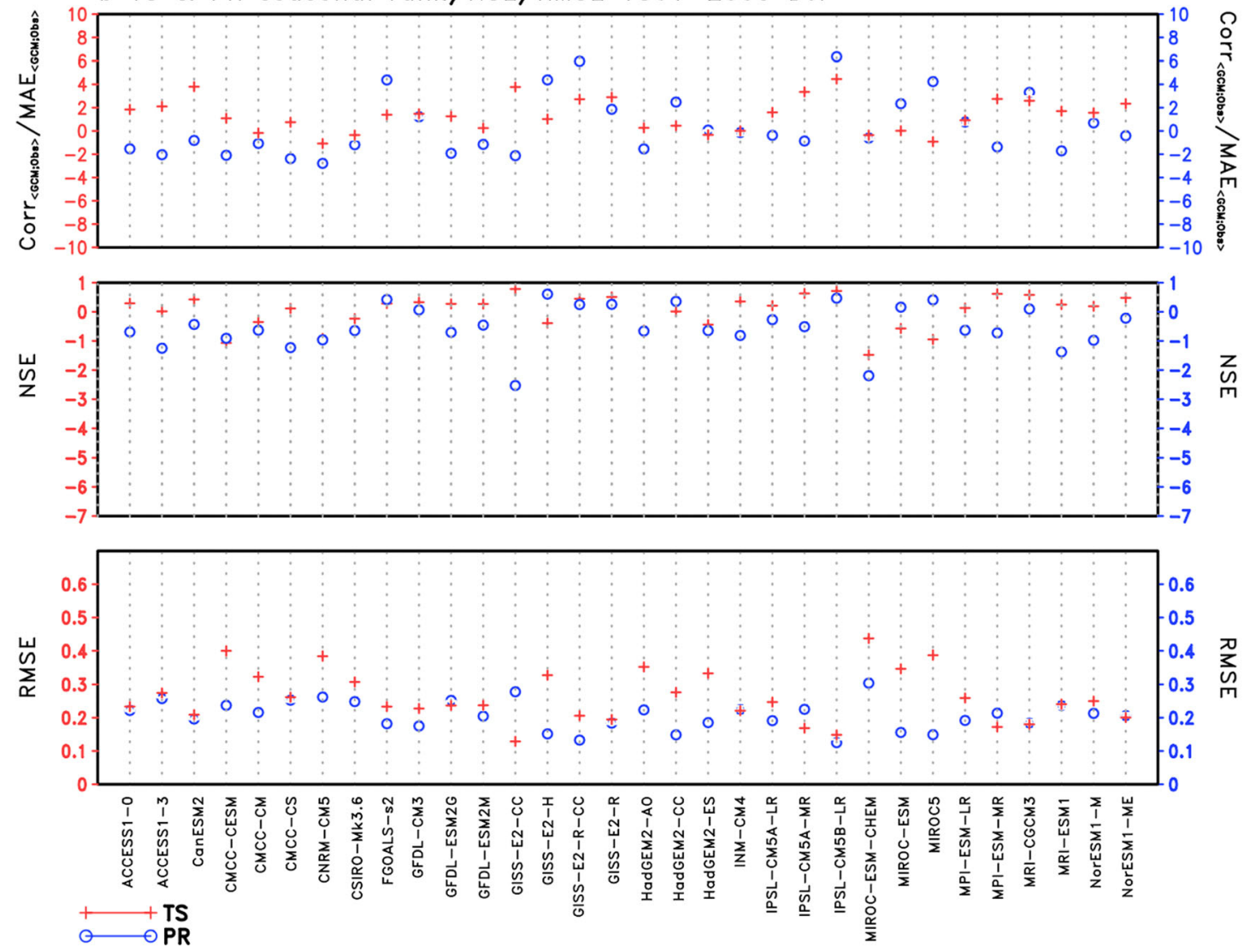
a TS \& PR mean rank/NSE/RMSE 1861-2005
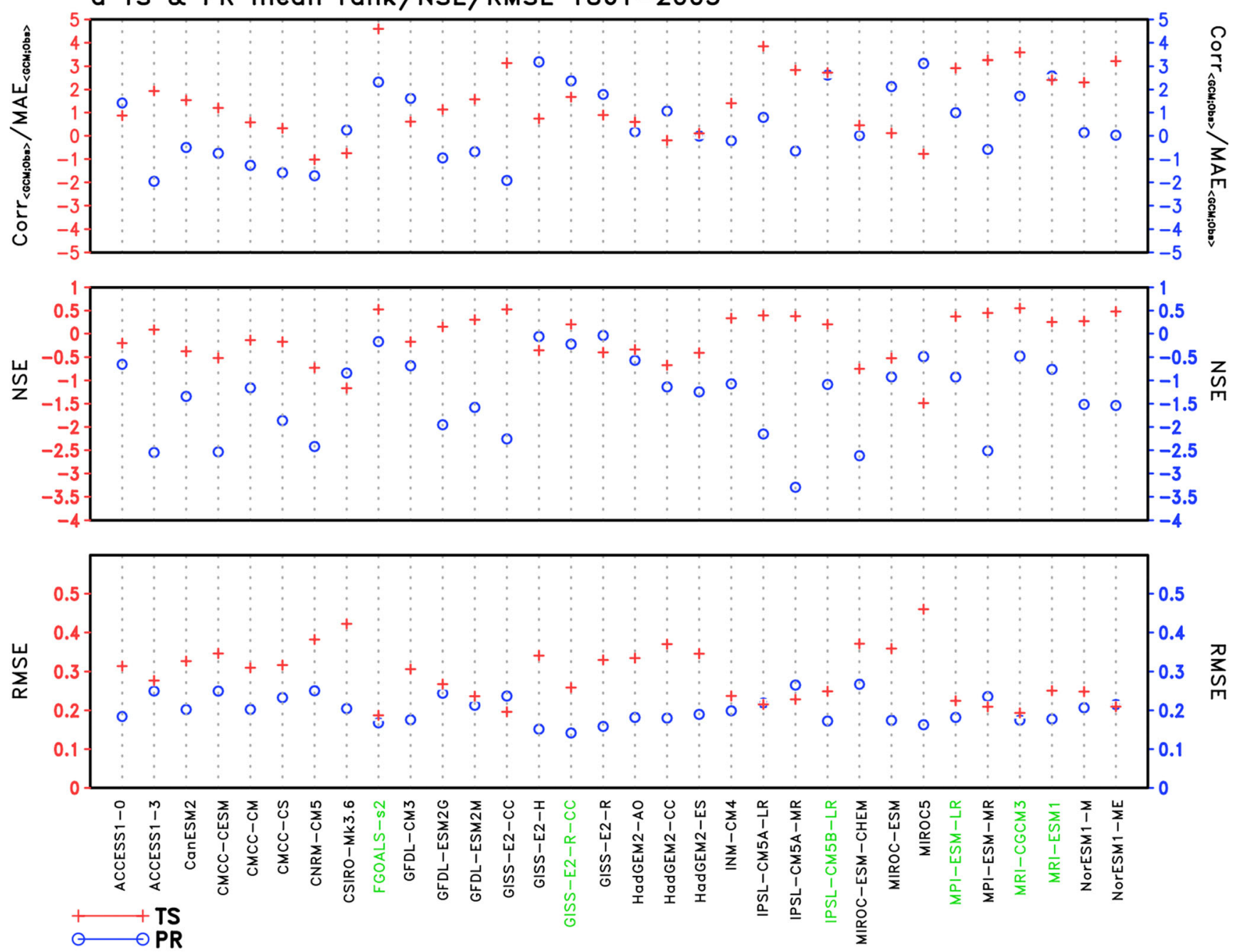

b Box-Whiskers of the grand rank/NSE/RMSE

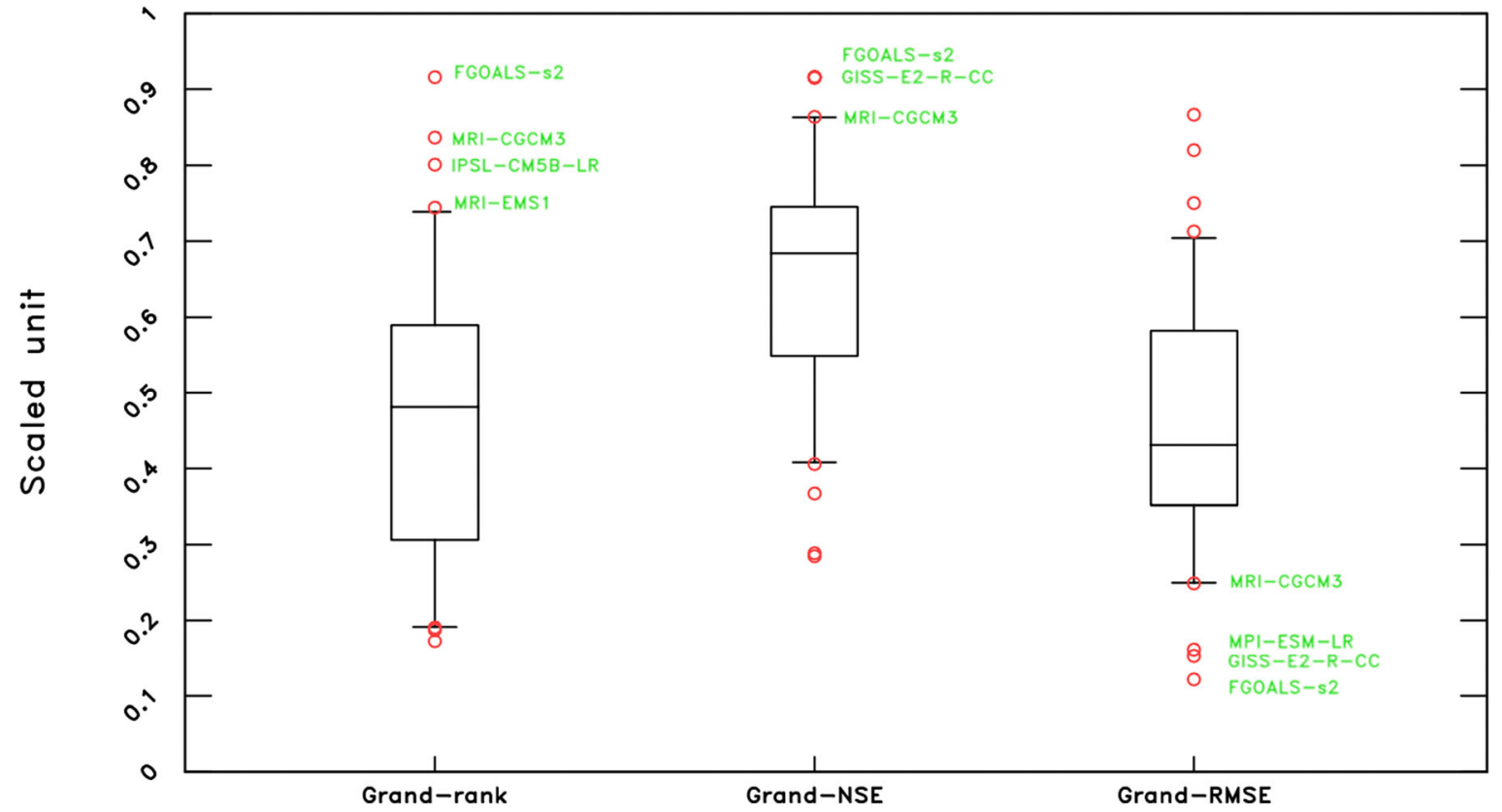


Fig. 4 a Surface temperature (TS) and precipitation (PR) mean ((JJA + $\mathrm{DJF}) / 2$ ) ranks (upper panel), mean NSE (middle panel), and mean RMSE (lower panel) for East-Central Europe for the historical era (1861-2005) across 32 CMIP5 climate models (indicated below the $\mathrm{x}$-axis). b Boxand-whiskers plot of the scaled [0;1] grand-rank, grand-NSE, and grandRMSE (indicated below the $\mathrm{x}$-axis) showing the 10th and 90th percentiles of 32 CMIP5 model's performances. Red circles show models above 90th and below 10th percentiles, respectively. Those six models above the 90th percentile in the grand-rank or -NSE or-RMSE are highlighted with green on a

by Auer et al. (2007) based on the regionalization of certain climatic variables. It was chosen to cover the region of interest (East-Central Europe), where precipitation projections of CMIP5 models show large spread for both summer (Fig. 2a) and winter (Fig. 2b). To ensure the robustness of results based on the primary target area, supplementary calculations were performed on an extended domain $\left(43^{\circ} \mathrm{N}-57^{\circ} \mathrm{N} ; 4^{\circ} \mathrm{E}-20^{\circ} \mathrm{E}\right.$; Fig. 1) corresponding to the East-Central European part of the area used in Vogel et al. (2018).

\subsection{HISTALP instrumental and the NOAA twentieth century reanalysis data}

For the basis of model assessment, we used monthly surface temperature (TS) and precipitation (PR) data from the HISTALP coarse resolution subregional mean (CRSM) series for the NE and SE subregions of the Greater Alpine Region (Fig. 1) for 1861-2005 (Auer et al. 2007; we refer to this data as observations). The CRSMs are arithmetic means of the

Table 3 Scaled $[0 ; 1$ ] grand-RMSE, -NSE, and -rank of 32 CMIP5 models for East-Central Europe. Models performing above the 90th percentile of the CMIP5 ensemble are italicized

\begin{tabular}{|c|c|c|c|c|c|}
\hline Model & Grand RMSE & Model & Grand NSE & Model & Grand Rank \\
\hline FGOALS-s2 & 0.12 & $F G O A L S$-s 2 & 0.92 & $F G O A L S-s 2$ & 0.92 \\
\hline GISS-E2-R-CC & 0.15 & $M R I-C G C M 3$ & 0.92 & $I P S L-C M 5 B-L R$ & 0.84 \\
\hline$M R I-C G C M 3$ & 0.16 & GISS-E2-R-CC & 0.91 & $M R I-C G C M 3$ & 0.8 \\
\hline$M P I-E S M-L R$ & 0.25 & MPI-ESM-LR & 0.86 & MRI-ESM1 & 0.74 \\
\hline IPSL-CM5B-LR & 0.26 & MRI-ESM1 & 0.86 & IPSL-CM5A-LR & 0.69 \\
\hline MRI-ESM1 & 0.28 & INM-CM4 & 0.8 & GISS-E2-R-CC & 0.68 \\
\hline INM-CM4 & 0.34 & IPSL-CM5B-LR & 0.78 & GISS-E2-H & 0.65 \\
\hline GISS-E2-H & 0.35 & NorESM1-M & 0.75 & MPI-ESM-LR & 0.64 \\
\hline NorESM1-ME & 0.35 & NorESM1-ME & 0.74 & NorESM1-ME & 0.57 \\
\hline GISS-E2-R & 0.35 & GISS-E2-H & 0.74 & MPI-ESM-MR & 0.57 \\
\hline GFDL-CM3 & 0.38 & GISS-E2-CC & 0.73 & GISS-E2-R & 0.57 \\
\hline IPSL-CM5A-LR & 0.38 & GISS-E2-R & 0.73 & GFDL-CM3 & 0.52 \\
\hline NorESM1-M & 0.39 & ACCESS1-0 & 0.72 & ACCESS1-0 & 0.51 \\
\hline GFDL-ESM2M & 0.40 & GFDL-CM3 & 0.72 & IPSL-CM5A-MR & 0.51 \\
\hline GISS-E2-H-CC & 0.42 & GFDL-ESM2M & 0.72 & MIROC5 & 0.49 \\
\hline ACCESS1-0 & 0.43 & HadGEM2-AO & 0.7 & GISS-E2-CC & 0.49 \\
\hline MPI-ESM-MR & 0.43 & CMCC-CM & 0.67 & MIROC-ESM & 0.48 \\
\hline HadGEM2-AO & 0.46 & IPSL-CM5A-LR & 0.66 & NorESM1-M & 0.48 \\
\hline MIROC-ESM & 0.47 & HadGEM2-ES & 0.63 & INM-CM4 & 0.47 \\
\hline CMCC-CM & 0.49 & MPI-ESM-MR & 0.63 & GFDL-ESM2M & 0.41 \\
\hline HadGEM2-ES & 0.51 & MIROC-ESM & 0.62 & HadGEM2-CC & 0.38 \\
\hline HadGEM2-CC & 0.52 & CanESM2 & 0.6 & CanESM2 & 0.35 \\
\hline CanESM2 & 0.52 & GFDL-ESM2G & 0.57 & HadGEM2-AO & 0.32 \\
\hline GFDL-ESM2G & 0.58 & CMCC-CMS & 0.55 & GFDL-ESM2G & 0.31 \\
\hline IPSL-CM5A-MR & 0.59 & HadGEM2-CC & 0.54 & HadGEM2-ES & 0.29 \\
\hline MIROC5 & 0.62 & ACCESS1-3 & 0.51 & CSIRO-Mk3.6 & 0.25 \\
\hline ACCESS1-3 & 0.62 & IPSL-CM5A-MR & 0.46 & MIROC-ESM-CHEM & 0.23 \\
\hline CMCC-CMS & 0.63 & MIROC5 & 0.43 & ACCESS1-3 & 0.2 \\
\hline CSIRO-Mk3-6-0 & 0.71 & CSIRO-Mk3.6 & 0.41 & CMCC-CM & 0.19 \\
\hline CMCC-CESM & 0.75 & CMCC-CESM & 0.37 & CMCC-CESM & 0.19 \\
\hline CNRM-CM5-2 & 0.82 & CNRM-CM5 & 0.29 & CMCC-CMS & 0.17 \\
\hline MIROC-ESM-CHEM & 0.87 & MIROC-ESM-CHEM & 0.28 & CNRM-CM5 & 0.01 \\
\hline
\end{tabular}



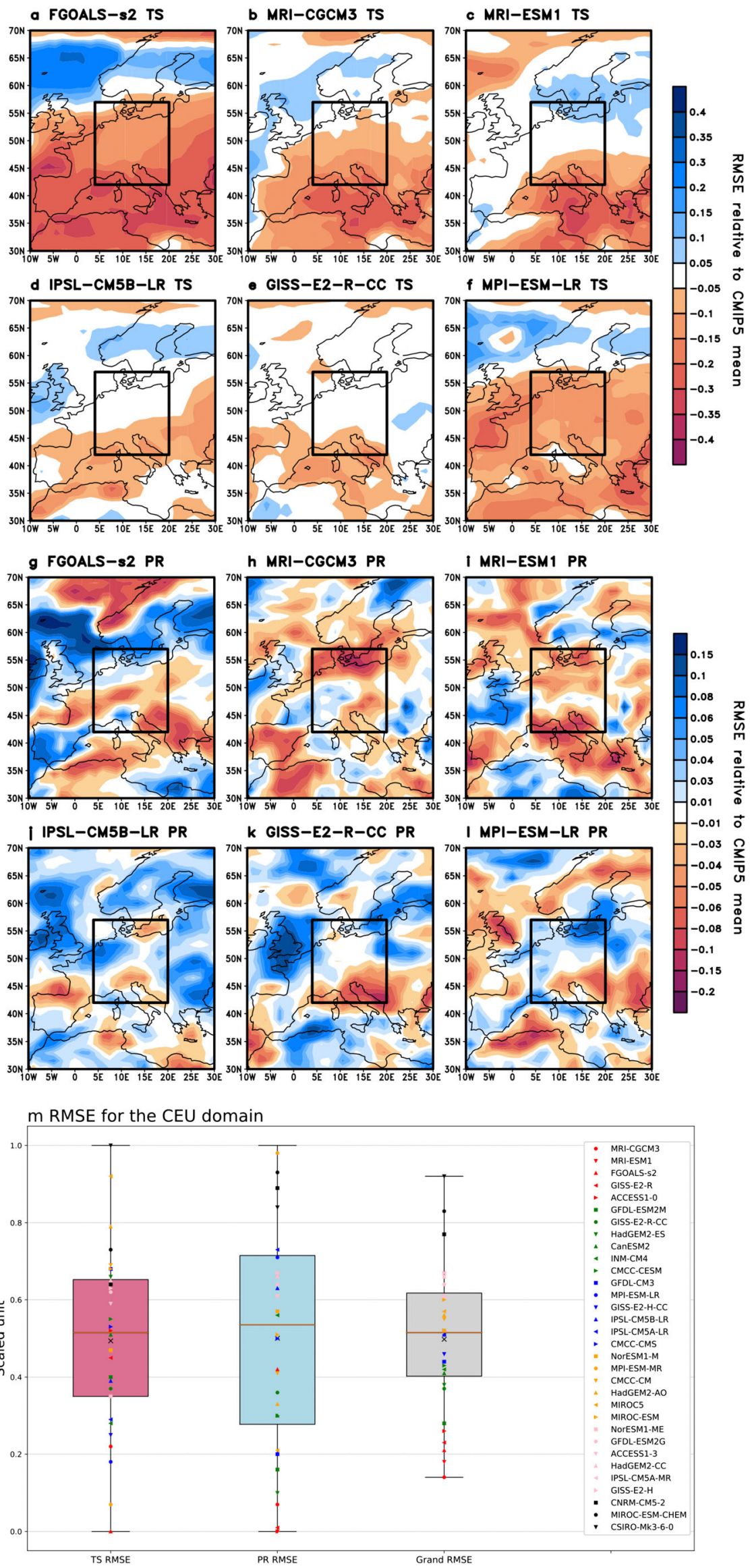
Fig. 5 Spatial map of $\mathbf{a}-\mathbf{f}$ surface temperature (TS) and $\mathbf{g}-\mathbf{I}$ precipitation (PR) RMSE based on the NOAA twentieth century reanalysis (18612005) relative to the CMIP5 ensemble mean shown for the top 6ranked models (based on historical instrumental data, see Methods) and m box-and-whiskers plot of the TS (violet) and PR (light blue) RMSE averaged for the Central European (CEU) domain $\left(43^{\circ}-57^{\circ} \mathrm{N} ; 4^{\circ} \mathrm{E}-20^{\circ} \mathrm{E}\right)$ and the average of the TS and PR RMSE values (Grand RMSE with gray) for 32 CMIP5 models each of which is marked as in the legend. The whiskers extend to the minimums and maximums. The median of each group is indicated with orange horizontal lines. The means are marked with $\times$

homogenized anomaly series (reference period: 1961-1990) for the stations situating within the boundaries of NE and SE subregions. We also utilize TS and PR data from the NOAA twentieth century reanalysis version 3 (Compo et al. 2011; Slivinski et al. 2019) for the assessment of model performance.

\subsection{CMIP5 models and single-model initial condition large ensembles}

For the analysis, we selected CMIP5 models that have socalled historical or future RCP8.5 simulations following the historical experimental design for 1861-2005 and RCP8.5 forcing scenario for 2006-2100 (Lamarque et al. 2010; Taylor et al. 2012b). This resulted in the selection of 32 different model versions for the historical and 31 models for the future timeframe from 16 modeling centers worldwide (Table 1). In addition, we made use of six SMILE simulations' future (2006-2080) precipitation simulations: Max Planck Institute Grand Ensemble (MPI-GE), Canadian Earth System Model Large Ensemble (CanESM-LE), Community Earth System Model Large Ensemble (CESM-LE), Geophysical Fluid Dynamics Laboratory Earth System Model version 2 Large Ensemble (GFDL_ESM2M-LE), Commonwealth Scientific and Industrial Research Large Ensemble (CSIRO-LE), and EC-EARTH Large Ensemble (EC_EARTH-LE). In addition, we used two historical (1861-2005) precipitation simulations of the MPI-GE and EC_EARTH-LE (further details and references are found in Table 2).

\subsection{Ranking the individual CMIP5 models}

As a preliminary step, model output was interpolated onto the same regular $1.5^{\circ}$ grid, and anomalies (relative to 1961-1990 to match the HISTALP anomaly time series) were calculated for all the individual historical CMIP5 simulations. Boreal summer (June-July-August: JJA) and winter (DecemberJanuary-February: DJF) averages were derived annually for both the CMIP5 historical (1861-2005) and future (20062100) simulations and the observations of TS and PR.
Additionally, both observational and model data were smoothed with a centralized 31-year moving average to mostly account for multidecadal low-frequency variability (as is the standard practice to minimize the effect of internal variability in single model realizations; e.g., McCabe and Palecki 2006; Senftleben et al. 2020) and to ensure comparability with the GCM data with relatively coarse grid resolution. Data preparation resulted in area-averaged and smoothed time series for the two subregions (NE and SE) for each mod$\mathrm{el}$, variable, and season along with the observed time series.

We used three statistics for the individual CMIP5 models' assessment with root-mean square error (RMSE) being the primary one in addition to the fraction of temporal Pearson correlation coefficient and mean-absolute error (referred to as: rank) and the Nash-Sutcliffe efficiency (NSE, Nash and Sutcliffe 1970) calculated between the observed and simulated time series. The reason we include temporal correlation is to measure to what extent simulated long-term (the time series are smoothed with a 31-year moving average) changes in PR and TS are in-phase with observations as it is expected for a model to reproduce observed low-frequency TS and PR changes. The NSE (Eq. 1) is calculated based on the observed (obs) and simulated ( $\operatorname{sim})$ time series pairs as:

$$
N S E=1-\frac{\sum_{i=1}^{n}(o b s-s i m)^{2}}{\sum_{i=1}^{n}\left[(o b s-(\overline{o b s})]^{2}\right.}
$$

where $n$ is the length of the timeseries and $(\overline{\mathrm{obs}})$ indicates the time-mean of the observed timeseries. The NSE ranges from $-\infty$ to 1 , where 1 would mean the perfect observation-simulation match (which is not possible) and NSE $=0$ indicates that the modeled time series' mean-square-error is commensurable with the variance of the observed time series.

For simplicity, we now only go through the ranking steps for the RMSE as the calculations are the same for the other two statistics. First, RMSE corresponding to each of the two seasons (JJA and DJF) was calculated for both variables (referred to as TS and PR seasonal RMSE) for the two subregions separately. Then, the RMSE values were averaged for the two subregions and seasons for the two variables separately (referred to as TS and PR mean RMSE). We also assess the overall performance of a model in reproducing the observed past hydroclimate variability in the target region and introduce the grand-RMSE, which is the average of the TS and PR mean RMSE values. To ensure comparability of the RMSE of PR and TS, we rescaled the values (for both variables) to range between 0 and 1 

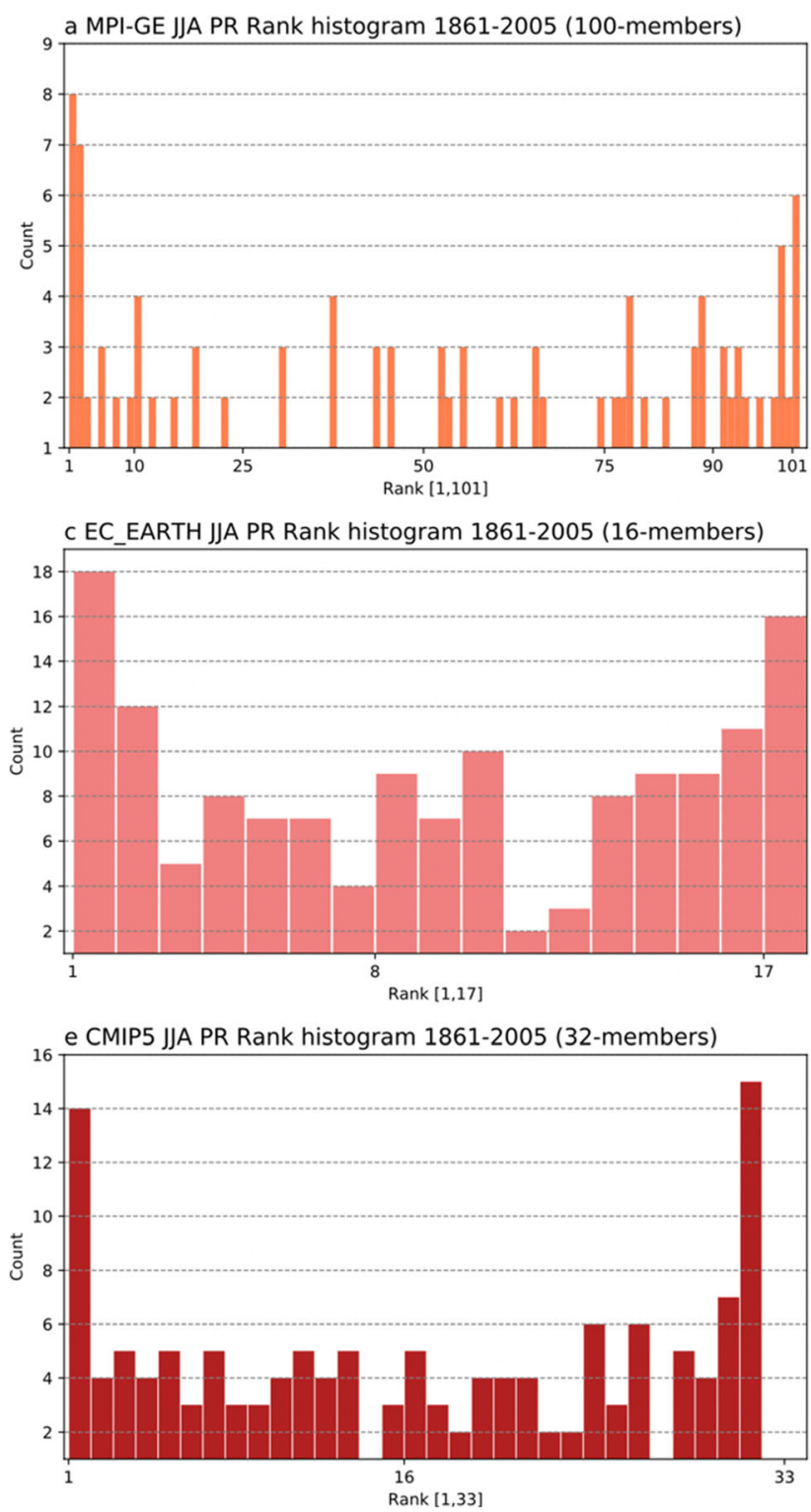
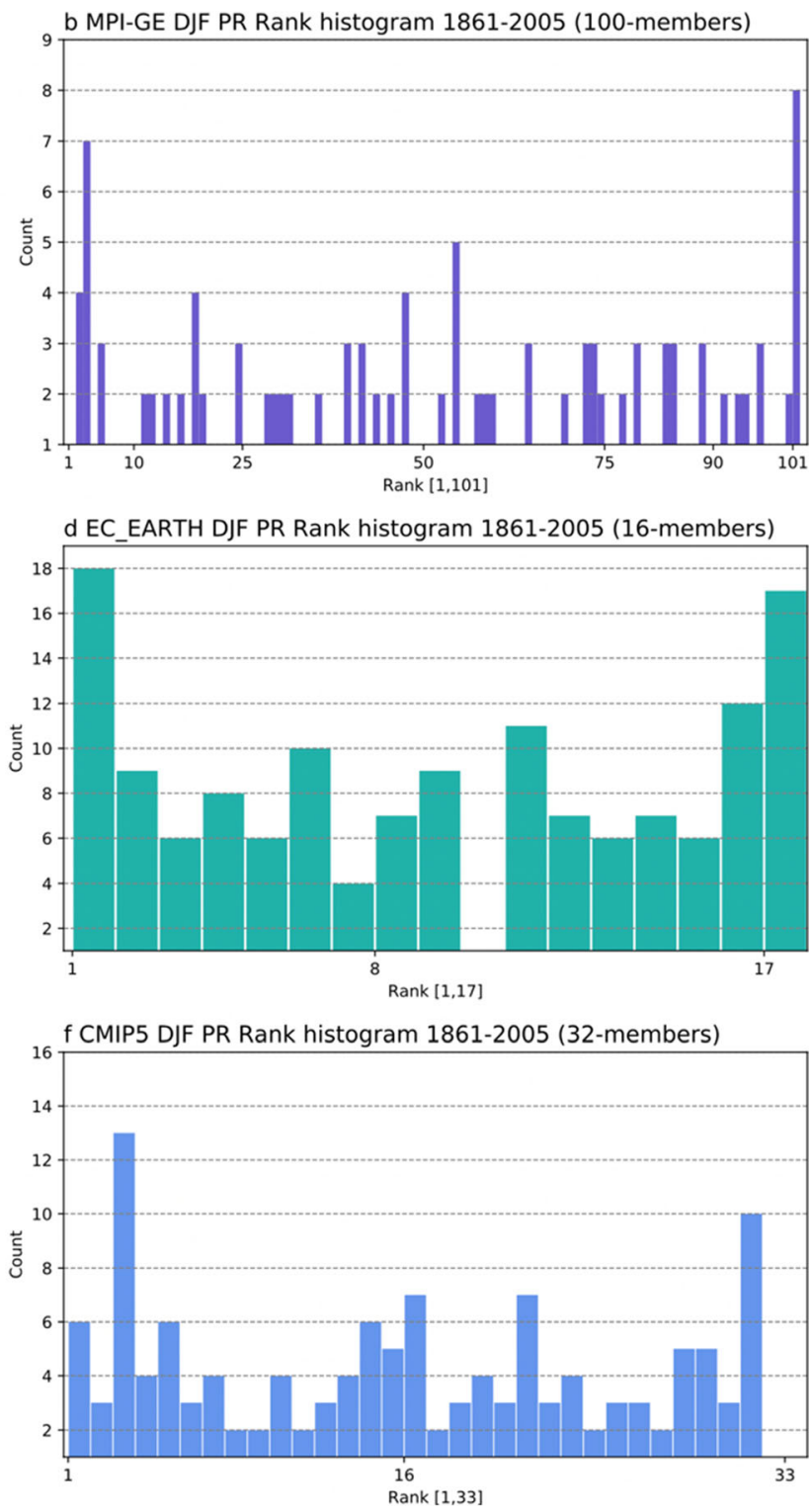

Fig. 6 Rank histograms based on the year-to-year seasonal mean HISTALP observed precipitation in the target area for two large ensembles a-b MPIGE and $\mathbf{c}-\mathbf{d}$ EC-EARTH-LE, and the CMIP5 multi-model ensemble $\mathbf{e}-\mathbf{f}$

(Eq. 2) before averaging them into the grand-RMSE, which is the arithmetic mean of the scaled mean RMSE of TS and PR.

$R M S E_{\text {scaled }}=\frac{\text { meanRMSE }-\min _{m=1, \cdots, M}(\text { meanRMSE })}{\max _{m=1, \cdots, M}(\text { meanRMSE })-\min _{m=1, \cdots, M}(\text { meanRMSE })}$

where $m$ goes through the $M=32$ CMIP5 models.Note that the applied rescaling is based on the maximum and minimum values of the mean RMSE to maintain the relative differences between each model's performances.

\subsection{Rank histogram to assess the performance of an ensemble}

Additionally, to assess the performance of an ensemble as a whole, we apply the rank histogram on year-to-year seasonal (JJA and DJF) averaged HISTALP and simulated data (Talagrand et al. 1997; Annan and Hargreaves 2010; Maher et al. 2019) for the two SMILEs with sufficiently long historical simulations (MPI-GE and EC_EARTH-LE) and for the CMIP5 ensemble. To do so, let us consider an ensemble with $n$ members and initially let the rank $=1$. At each time-step (18612005), we count the number of members of a given ensemble that are greater than the observed value at that 
Fig. 7 Time series of standardized (relative to 19712000 mean) seasonal mean precipitation (PR) for 2021-2085 (31-year moving averaged) for the members of the constrained CMIP5 ensemble (colored solid lines) and the mean of $31 \mathrm{CMIP5}$ models (thick solid gray line) in addition to the 31 individual models in CMIP5 (thin solid gray lines) for the primary target area (blue box on Fig. 8: $43^{\circ} \mathrm{N}-50^{\circ}$ $\left.\mathrm{N} ; 13^{\circ} \mathrm{E}-19.5^{\circ} \mathrm{E}\right) \mathbf{a}$ for JJA and $\mathbf{b}$ for DJF a 31 CMIP5 PR JJA 2021-2085
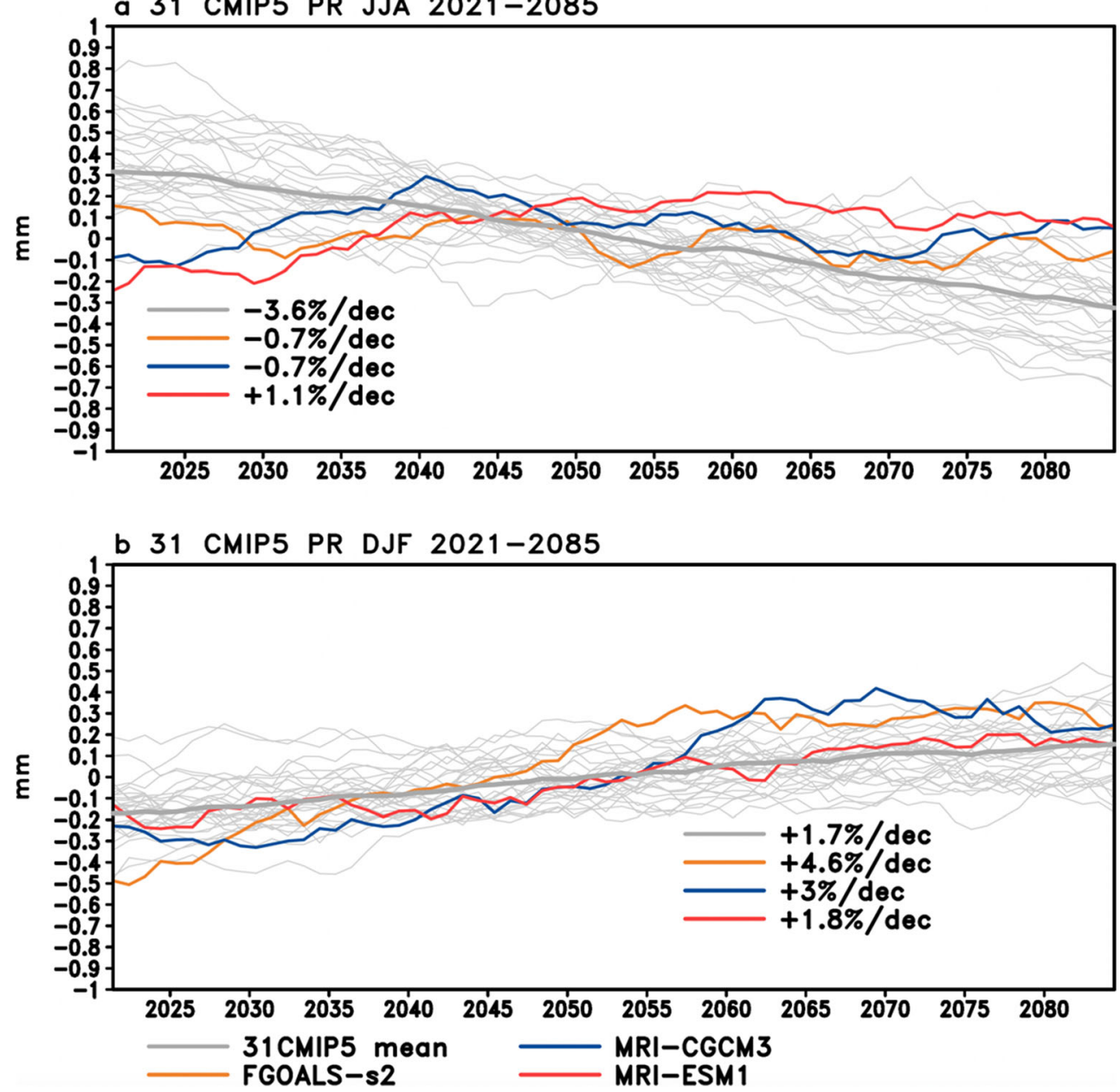

time-step, which can be between count $=0$ and count $=n$. If count $=0$, then the $\operatorname{rank}=1$, or if count $=n$, then the rank $=n+1$, else the rank $=$ count. We plot the histogram of the ranks and check for consistency with uniformity based on a chi-squared test (Annan and Hargreaves 2010). If the ensemble underestimates the observed variability, then observations will frequently lie close to, or outside the edges of the ensemble resulting in a u-shaped rank histogram, while a well performing ensemble would yield a flat rank histogram.

\section{Using observations to constrain the CMIP5 ensemble}

\subsection{Ranking CMIP5 models based on their historical performance (1861-2005)}

To begin with, we assess the historical performance of 32 CMIP5 models based on the HISTALP observations (1861-2005) and use the above described ranking method. At first, seasonal RMSE, rank, and NSE were calculated for the NE and SE subregions for both seasons separately, then averaged over the primary target area (Fig. 3). The 32 CMIP5 models show diverging performance in capturing past seasonal TS and PR variability (Fig. 3). Some models (e.g., FGOALS-s2; MRI-CGCM3) stand out from others, suggesting that abandoning the "one model one vote" approach (Knutti 2010) is a right decision for the target area. The spread between the performances of the models are larger in summer (Fig. 3a) than in winter (Fig. 3b), which discrepancy might be rooted in that (i) summertime convective precipitation is more challenging for GCMs to capture (Dai 2006) and (ii) that the regional surface temperature warming signal over the past decades is more pronounced in summer than in winter. For some of the models (e.g., CanESM2; CSIROMk3.6) the seasonal rank is negative, along with higher seasonal RMSE values. The negative rank means negative correlation between the observed and simulated time series, which is indicative of that the model is out of phase with the long-term observed changes.

In the next steps, first, we average the seasonal statistics and obtain the mean RMSE, rank, and NSE (Fig. 4a) 


\section{JJA}

a FGOALS-s2 TS trend JJA

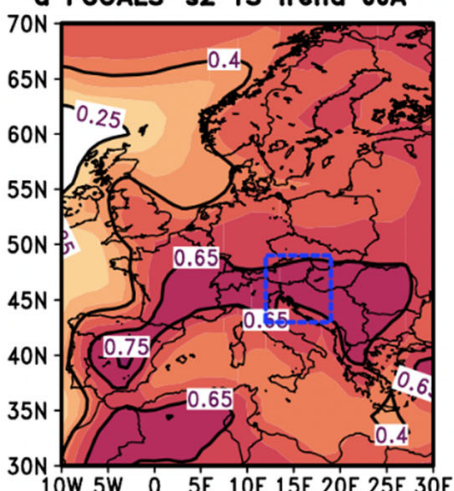

d FGOALS-s2 PR trend JJA

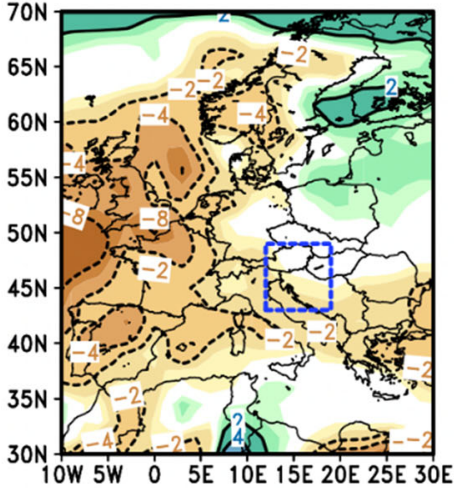

b MRI-CGCM3 TS trend JJA

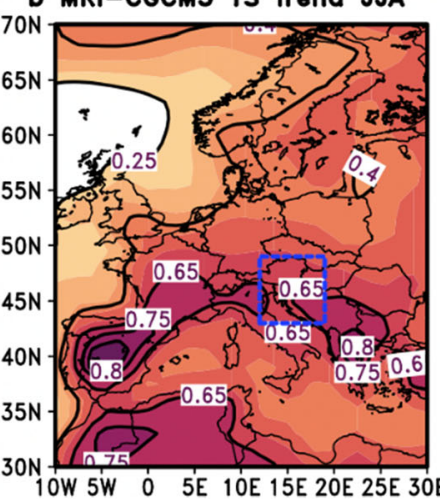

c MRI-ESM1 TS trend JJA

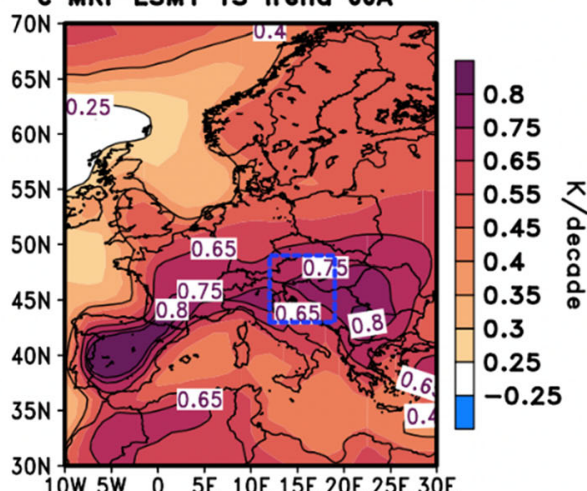

- MRI-CGCM3 PR trend JJA

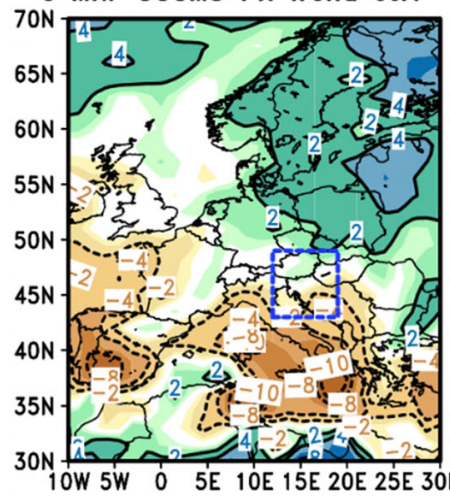

f MRI-ESM1 PR trend JJA

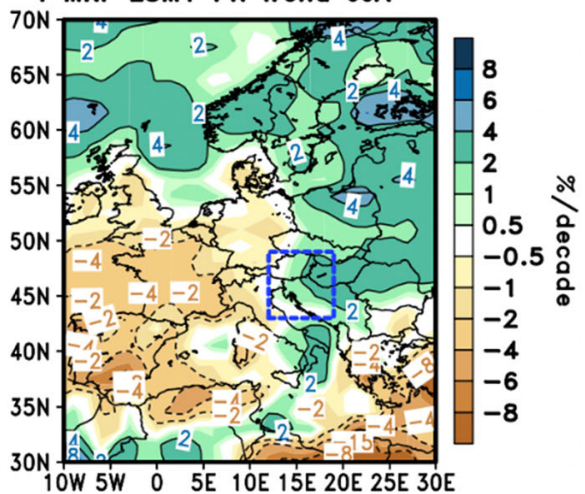

DJF
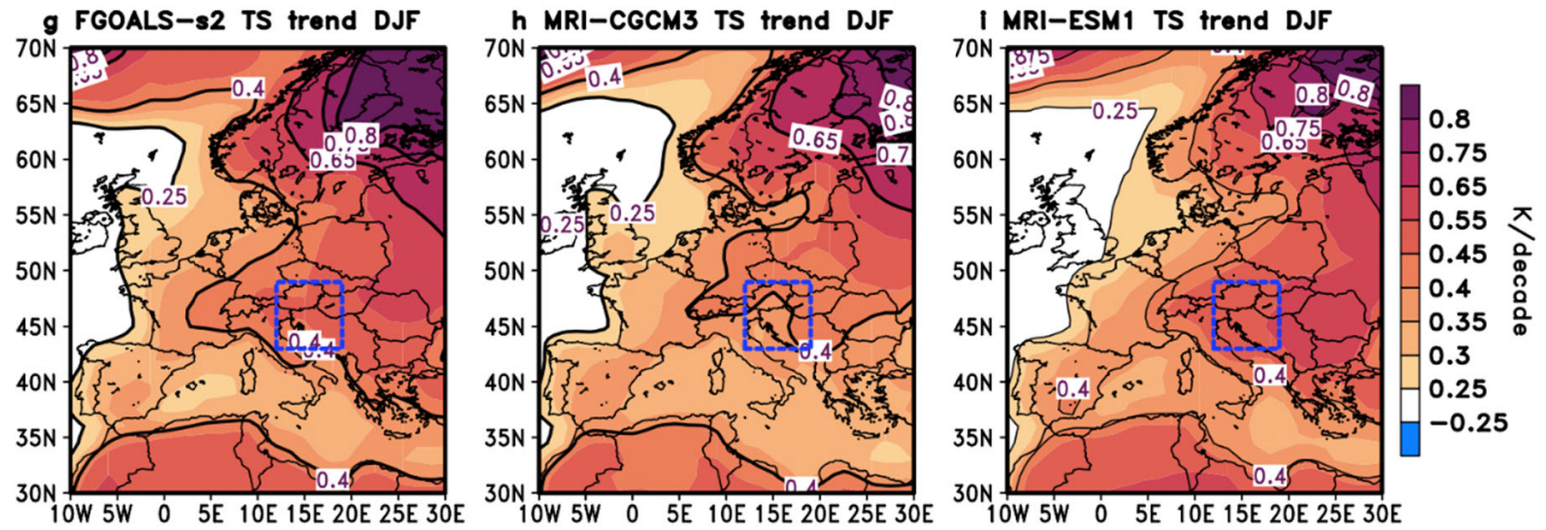

k MRI-CGCM3 PR trend DJF

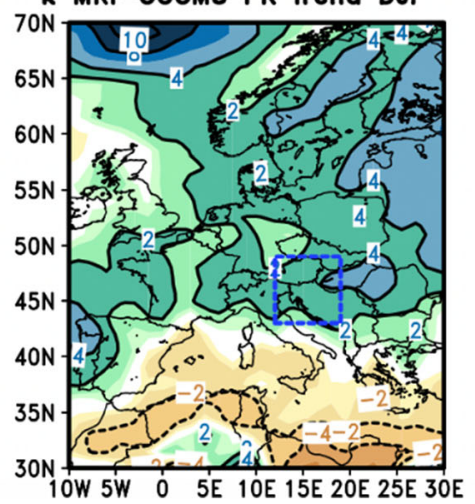

I MRI-ESM1 PR trend DJF

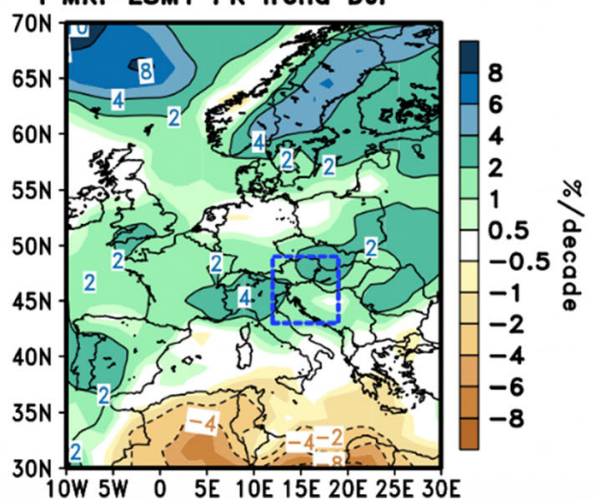


Fig. 8 Spatial map of the linear trend (relative to 1971-2000 mean) of a$\mathbf{c}$ and $\mathbf{g}-\mathbf{i}$ surface temperature (TS: $\mathrm{K} /$ decade) and $\mathbf{d}-\mathbf{f}$ and $\mathbf{j}-\mathbf{l}$ precipitation (PR: \%/decade) for 2021-2085 (31-year moving averaged) under RCP8.5 scenario in the members of the constrained CMIP5 ensemble (see Methods for ranking details) for JJA and DJF

per variable, second, re-scale them to range from 0 to 1 based on Eq. 2 and third, via averaging the re-scaled mean RMSE, rank, and NSE values, we obtain the grand-RMSE, -rank, and -NSE (Fig. 4b). Those models that performed above the 90th percentile of the CMIP5 ensemble based on any of the three metrics - a total of six models (FGOALS-s2; IPSL-CM5B-LR; MPI-ESMLR; MRI-CGCM3; MRI-ESM1; GISS-E2-R-CC) - are selected that skillfully reproduce multidecadal TS and PR variability over the past $\sim 150$ years in East-Central Europe (Fig. 4b; Table 3). To get a more visual picture of the six top performing models' past climate variability, 31-year moving averaged TS and PR time series for 1861-2005 are plotted against the HISTALP observations for both JJA and DJF for the two Greater Alpine subregions, separately (Fig. S1). Overall, models show large spread in their historical projections in the two subregions for both variables and seasons, which are visibly reduced among the six selected models (see the colored solid lines in Fig. S1).

\subsection{Validation of the ranking based on the NOAA twentieth century reanalysis}

To account for possible obscuring effects of the moderate size of the primary target area on the selection of the best performing models, we repeat the ranking using only the RMSE statistic for the extended domain (section 2.1; Fig. 1) based on the NOAA twentieth century version 3 gridded reanalysis (Slivinski et al. 2019). The calculation method is equivalent to the one applied to the HISTALP records except the 32 CMIP5 models are evaluated against the gridded reanalysis product. In Fig. 5, we demonstrate the spatial distribution of the reanalysis-based TS/PR mean RMSE relative to the CMIP5 multi-model ensemble mean for the six previously selected models (Fig. 5a-1) and show the TS/PR mean RMSE and the grand-RMSE for each model averaged over the extended target area (Fig. 1) as a box-and-whiskers plot (Fig. 5m). Spatial maps of the TS/PR mean RMSE for each of the 32 models are additionally shown in Fig. S2. Based on the grand-RMSE for the extended target area (Fig. $5 \mathrm{~m}$ ), only three out of the previously selected six models exhibit similar good overall performance; thus, we further reduce the range of selected models to the MRI-CGCM3, MRIESM1, and FGOALS-s2 and refer to them as the constrained ensemble.

\subsection{Rank histograms}

Furthermore, since internal variability cannot be correctly assessed in a multi-model ensemble because of the initial condition problem and differences in model structures (Branstator and Teng 2010; Knutti 2010; Bódai and Tél 2012), it must be considered that it may leave its fingerprint on our ranking and study rank histograms of historical precipitation projections of the MPI-GE and EC_EARTH-LE in the primary target area. Figure $6 \mathrm{a}-\mathrm{d}$ exhibit that both SMILEs underestimate the observed summer and winter precipitation variability (histograms are u-shaped), which is reinforced by the chi-squared tests indicating significant differences from uniformity (on the 99\% confidence level). Additionally, the CMIP5 multi-model ensemble shows similar rank histograms to the SMILEs' (Fig. $6 \mathrm{e}-\mathrm{f}$ ), except that the winter rank histogram does not differ significantly from a flat one. These indicate that (i) conclusions based on simulated internal variability by these two state-of-the-art SMILEs (and possibly by the others as well) should be treated with caution and that (ii) observational constraints may indeed be helpful in revealing models with structural advances relative to other models. In the upcoming sections, we further elucidate these issues.

\section{A possible source for a reduced projection spread: land-atmosphere couplings}

We are particularly concerned with how future projections of the constrained model ensemble look like in East-Central Europe. We find that not only did the ranking result in a reduced spread in historical simulations (Fig. S1), but the members of the constrained ensemble also show reduced spread in their future projections relative to the CMIP5 ensemble mean for both summer (Fig. 7a) and winter (Fig. 7b). Moreover, the difference between the CMIP5 ensemble mean (28 models' mean: $-3.9 \% /$ decade) and the constrained ensemble mean (3 models' mean: $-0.1 \% /$ decade) future precipitation trend is significant based on a two-sample $t$ test $(99 \%$ confidence level). The three top-ranked models indicate less dry summer and wetter winter conditions in the upcoming decades not only in the primary target area but also on the extended domain in parallel with considerable surface temperature rise (Fig. 8). Members of the constrained CMIP5 ensemble indicate -0.7 to $+1 \%$ /decade summer and +1 to $+5 \%$ / decade winter precipitation change for East-Central Europe relative to 1971-2000 (Fig. 8). Examining the constrained ensemble members' future seasonal surface temperature projections, we find no noticeable differences relative to the CMIP5 ensemble mean; therefore, we rule out the possibility that the discrepancy in future precipitation projections may be due to a negative surface temperature bias in those models (Fig. 8). 

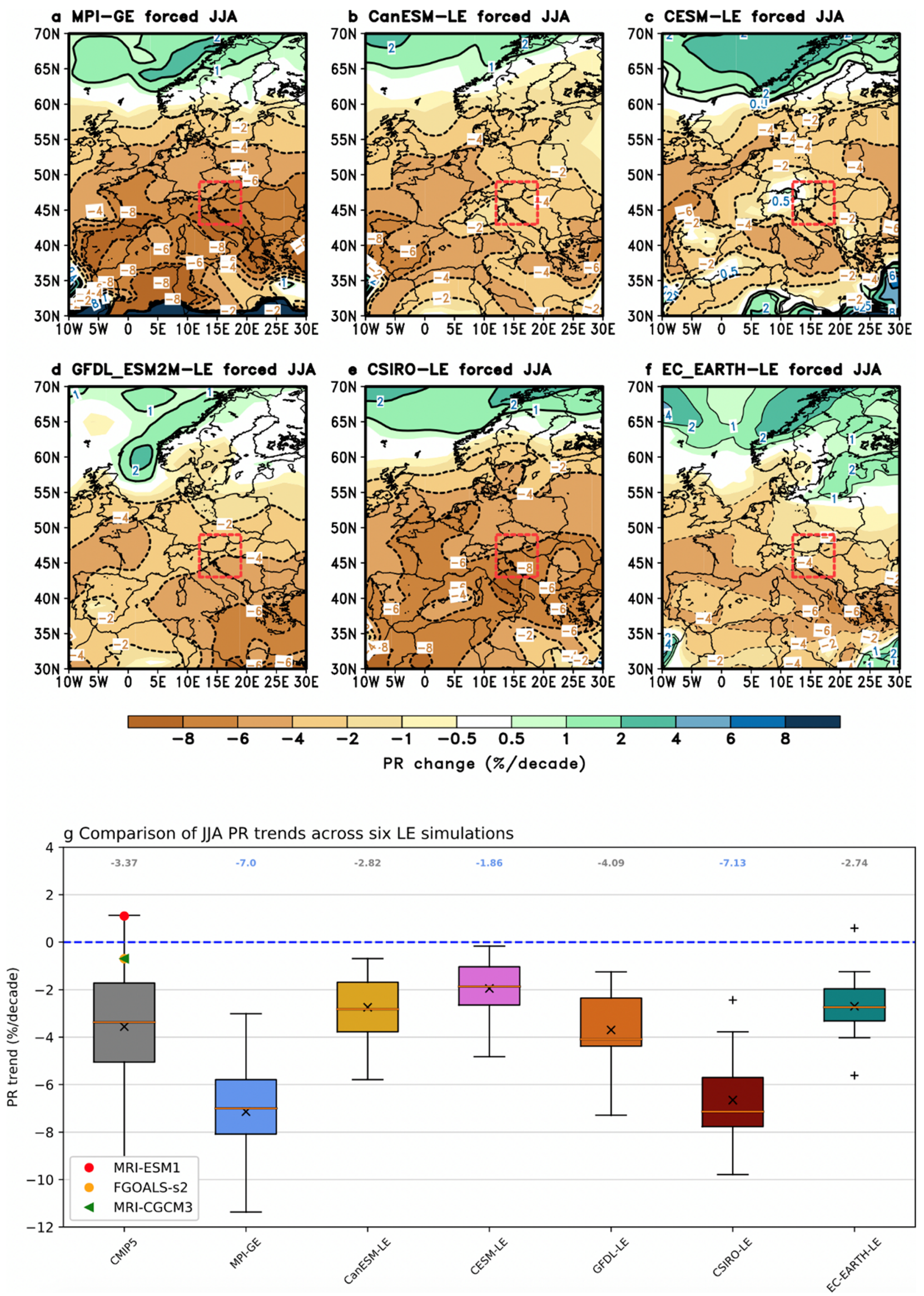
Fig. 9 Above: a-f spatial map of the ensemble mean (forced component) linear trend (relative to 1971-2000) of summer (June-July-August: JJA) precipitation for 2021-2085 (31-year moving averaged) for the six SMILEs. Below: $\mathbf{g}$ box-and-whiskers plot (with the whiskers extending to $1.5 \times$ interquartile range) of JJA precipitation linear trends (relative to $1971-$ 2000) for 2021-2085 (31-year moving averaged) for the CMIP5 multi-model and the six SMILEs (indicated below the $\mathrm{x}$-axis) for the primary target area (indicated by the red rectangles on $\mathbf{a}-\mathbf{f}: 43^{\circ} \mathrm{N}-50^{\circ} \mathrm{N} ; 13^{\circ} \mathrm{E}-19.5^{\circ} \mathrm{E}$ ). The median of each ensemble is indicated with numbers above the boxes in addition to the orange lines. The means are marked with $\times$, while the outliers (extending $1.5 \times$ interquartile range) are marked with + . Trend values of the members of the constrained CMIP5 ensemble are indicated with markers on the first box-and-whiskers

Our results are partly at odds with previous expectations that project extensive summer drying in the Central European region (Feng and Fu 2013; Sheerwood and Fu 2014; Polade et al. 2015; Pfleiderer et al. 2019). One mechanism for the advanced summer aridification in the region has been associated with the moist lapse-rate feedback due to global warming (Brogli et al. 2019). A warmer atmosphere, deduced from Clausius-Clapeyron relation, can hold more moisture, which, during moist adiabatic vertical motions, allows enhanced latent heat release and thus upper-tropospheric warming. These altogether result in an increased dry atmospheric static stability as the thermal stratification remains close to the moist adiabat during summer (Schneider 2007; Brogli et al. 2019). Another mechanism regarding changes in atmospheric circulation regimes, such as the poleward shifted subsidence zone with the projected expansion of the Hadley-cell, has also been suggested to influence future hydroclimate in the region due to enhanced radiative forcing (Perez et al. 2014; Mann et al. 2018). Nevertheless, inconclusive literature (e.g., Kröner et al. 2017) hinders us from a complete understanding of possible future precipitation changes in transitional climatic zones, such as Central Europe.

Recent studies highlight a competing role for landatmosphere interactions and the extent of its realistic representation in climate models in determining future hydroclimate uncertainty in the Mediterranean and Central Europe, where soil moisture largely affects temperature and precipitation via the partitioning of net radiation into sensible and latent heat fluxes (Boberg and Christensen 2012; Lorenz et al. 2016; Vogel et al. 2018; Al-Yaari et al. 2019; Selten et al. 2020). It has also been proposed that it is not enough for a model to faithfully represent observed soil-atmosphere feedbacks because convection, land-surface, and cloud parametrization schemes not only influence how soil moistureprecipitation feedbacks are handled in a model but also affect soil moisture-temperature feedbacks in turn (Christensen and Boberg 2012). This further complicates and highlights the importance of land-atmosphere interactions in determining future hydroclimate uncertainty in our target region.

Members of our constrained CMIP5 ensemble belong to the group of CMIP5 models that was identified by Vogel et al.
(2018) with (i) more fidelity in representing land-atmosphere couplings and (ii) less pronounced summer hot and dry extremes for central Europe. A physical mechanism strongly connected to land-atmosphere feedbacks that might balance the decrease in precipitation during future transition into semiarid regions in Central Europe was also suggested (Taylor et al. 2012a). In an early study, Dai (2006) showed that a previous version of MRI-CGCM3 (the MRI-CGCM version 2.3.2a) better captured observed global rainfall patterns than other models indicating that some basic features rooted in the model physics (most likely the convective and stratiform precipitation parametrization schemes) can indeed be sources of intermodel spread.

These lines of evidence reinforce the idea of ranking to constrain future hydroclimate projections of different CMIP5 models based on evaluating their historical performance and suggest an important physical mechanism that can explain why our selected models perform better regionally. Furthermore, presented results provide valuable implications for future RCM simulations and advocate future research to revisit the problem of the fidelity of land-atmosphere feedbacks in RCM simulations, where the enhanced resolution allows for a more detailed picture of regional feedback mechanisms.

Although the 32 GCMs differ in their external forcing components for their historical simulations, no pronounced differences are observable between the members of the constrained and the CMIP5 ensemble (not shown). We argue that the varying historical model projection skills are not primarily rooted in the differences between the external forcing components in line with previous studies, e.g., Reichler and Kim (2008). Nevertheless, we note that the choice of the external forcing scenario does influence future model projections (Santer et al. 2018), especially under a changing climate, when the external forcing components are timedependent (Bódai et al. 2020; Haszpra et al. 2020a,b).

\section{Placing future precipitation projections of the constrained ensemble in the context of SMILE projections}

Based on the ranking, we identified a constrained CMIP5 multi-model ensemble that shows reduced spread in their historical and future precipitation projections indicating less dry summer and wetter winter conditions in the upcoming decades (Figs. 7 and 8). We have also seen that land-atmosphere feedbacks may be of key importance in explaining why some models perform better than others. The advantage of including SMILE simulations in our study is to provide an estimate (i) for the forced response (ensemble mean) in precipitation to greenhouse gas emissions and (ii) for all possible states 


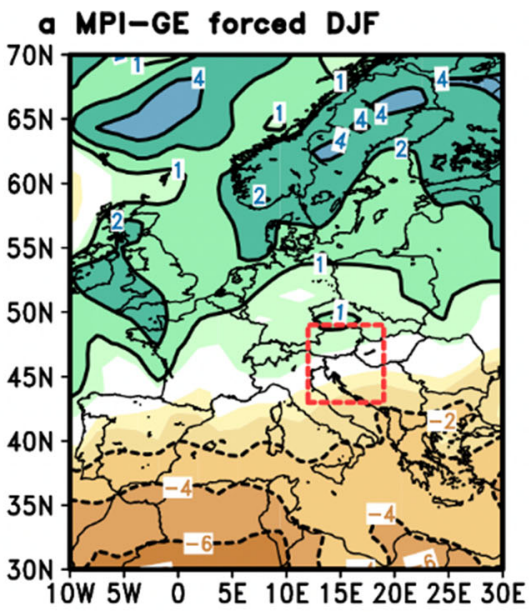

b CanESM-LE forced DJF

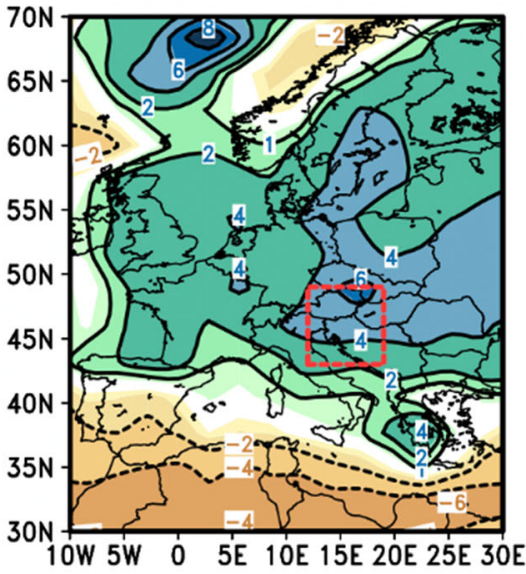

d GFDL ESM2M-LE forced DJF

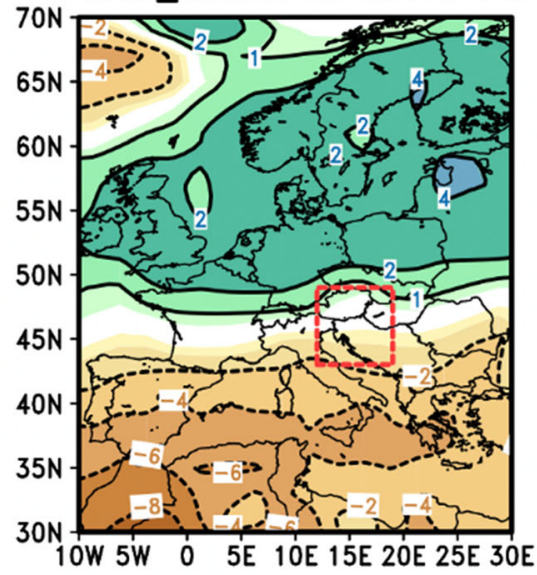

- CSIRO-LE forced DJF

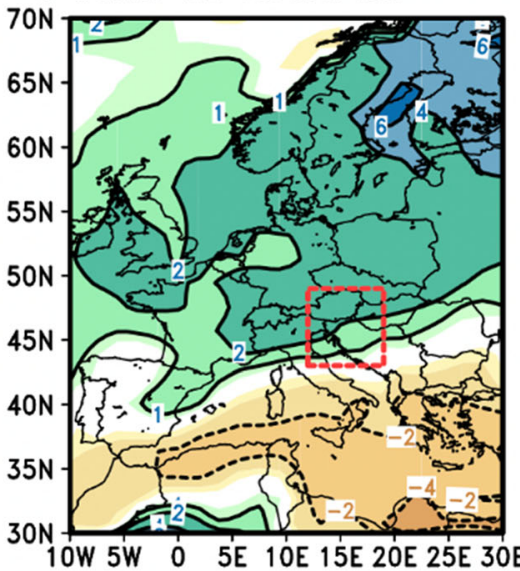

c CESM-LE forced DJF

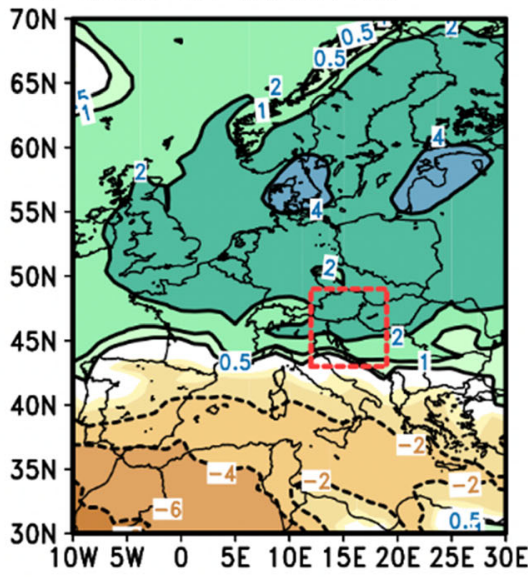

$f$ EC_EARTH-LE forced DJF

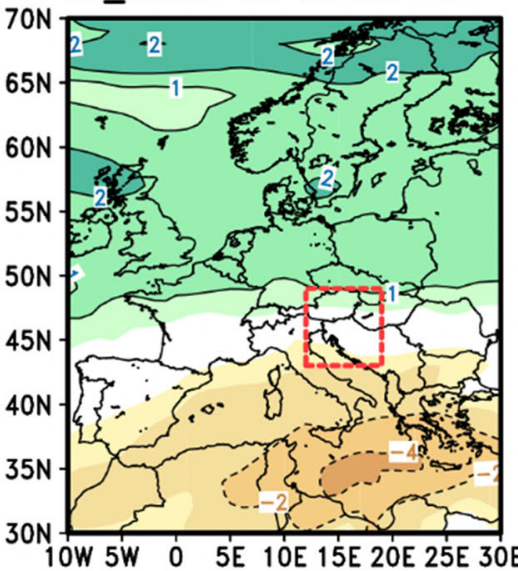

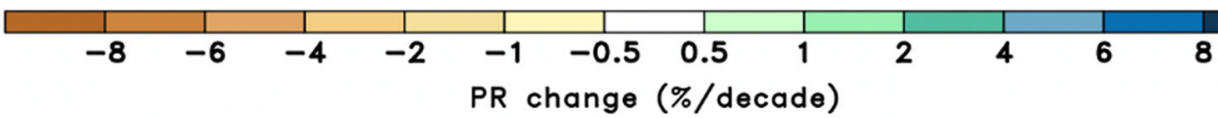

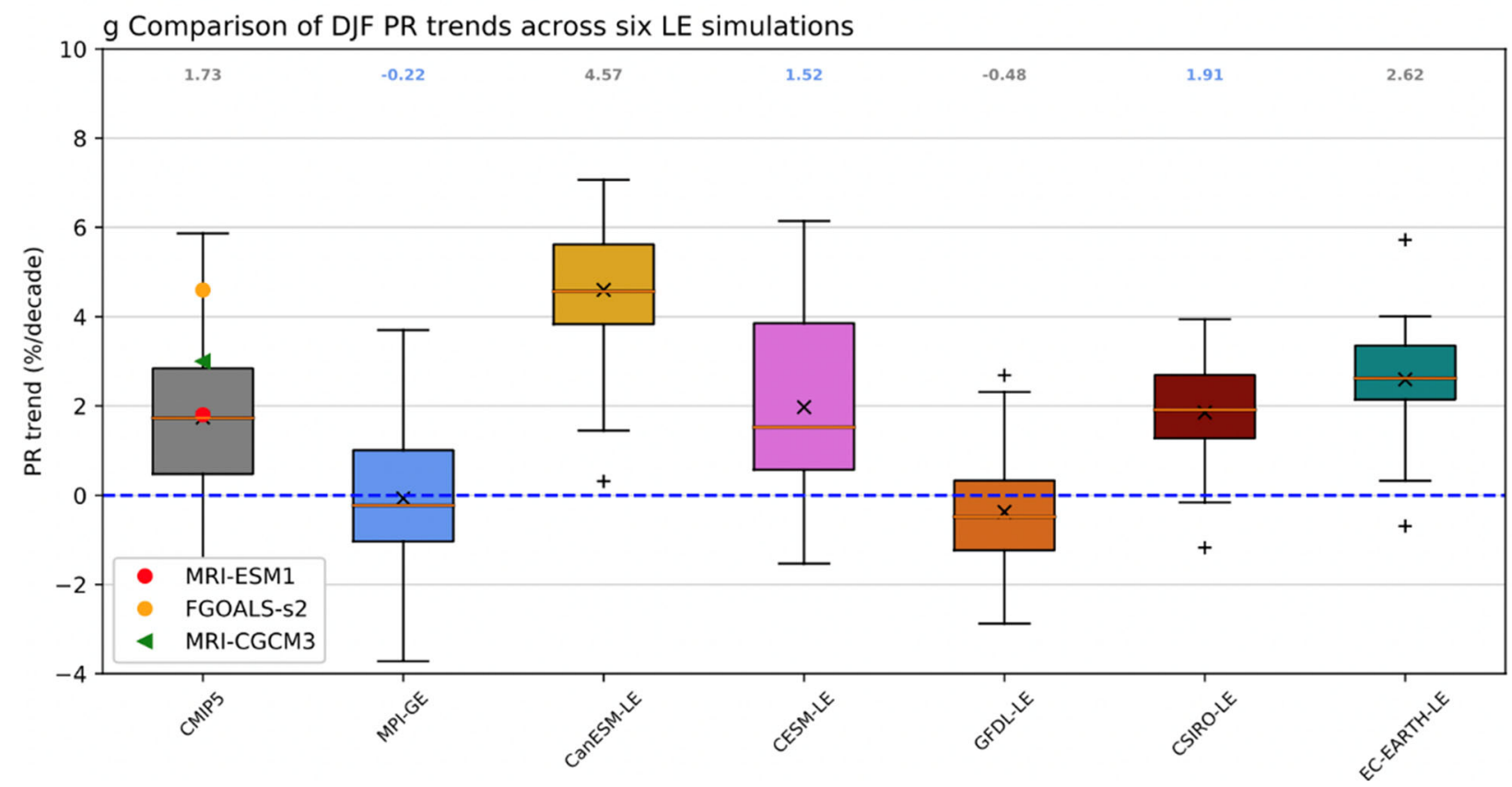


Fig. 10 Above: a-f spatial map of the ensemble mean (forced component) linear trend (relative to 1971-2000) of winter (DecemberJanuary-February: DJF) precipitation for 2021-2085 (31-year moving averaged) for the six SMILEs. Below: $g$ box-and-whiskers plot (with the whiskers extending to $1.5 \times$ interquartile range) of DJF precipitation linear trends (relative to 1971-2000) for 2021-2085 (31-year moving averaged) for the CMIP5 multi-model and the six SMILEs (indicated below the $\mathrm{x}$-axis) for the primary target area (indicated by the red rectangles on a-f: $43^{\circ} \mathrm{N}-50^{\circ} \mathrm{N} ; 13^{\circ} \mathrm{E}-19.5^{\circ} \mathrm{E}$ ). The median of each ensemble is indicated with numbers above the boxes in addition to the orange lines. The means are marked with $\times$, while the outliers (extending $1.5 \times$ interquartile range) are marked with + . Trend values of the members of the constrained CMIP5 ensemble are indicated with markers on the first boxand-whiskers

allowed by internal variability in a certain model (ensemble spread), which allows us to place the observationally constrained CMIP5 ensemble (three top-ranked models) in the context of internal variability. What is more, with the inclusion of six SMILEs, we can compare the internal variability of projected precipitation of various models, thus, get a more robust estimate of future states of hydroclimate allowed by internal variability in the region. We are aware of caveats added by the coarse spatial and topography resolution of SMILEs; however, currently, it is our best estimate for projected hydroclimate uncertainty due to internal variability.

We plot the spatial map of the ensemble mean future precipitation projections' linear trends for Europe and the spread across all members of the ensembles as a box-and-whiskers plot for our primary target area (Fig. 1) for summer (Fig. 9) and winter (Fig. 10). In summer, all SMILE mean simulations show drier future conditions in East-Central Europe indicating -2 to $-7 \% /$ decade precipitation decrease during the upcoming decades relative to 1971-2000 (Fig. 9), while the constrained CMIP5 ensemble mean trend indicates less pronounced summer drying $(-0.1 \%$ / decade). However, the magnitudes of the ensemble mean projections and the ensemble spread of different SMILE simulations vary considerably across the six SMILEs that implies a role for model uncertainty in regulating future hydroclimate changes on top of internal variability. Furthermore, the constrained ensemble's mean future (2021-2085) precipitation trend $(-0.1 \% / \mathrm{de}$ cade) emerges from the interquartile range of simulated internal variability by six SMILEs $((-8 \%,-1 \%) /$ decade $)$. The difference between the group of future precipitation trends spanned by all the members of the six SMILEs (a total of 256 members) and the constrained ensemble ( 3 members) is significant based on a twosample $t$ test on the $99 \%$ confidence level (the means of the two groups' trends: $-4.8 \%$ /decade for the six SMILEs and $-0.1 \%$ / decade for the constrained ensemble).

Since we used observations to constrain the CMIP5 ensemble, which resulted in the selection of models with more realistic representations of land-atmosphere feedbacks, we assume that the difference between the constrained ensemble's and the six SMILEs' future summer precipitation trends may be attributable to land-atmosphere coupling discrepancies between the models. Importantly, except for the CESM1, the base models of the large ensemble simulations were either involved in the ranking, or we evaluated their historical simulations (see Sect. 3.3). Thus, it is unlikely that the SMILE simulations would regionally outperform the members of the constrained CMIP5 ensemble in capturing observed precipitation variability. Although this needs further efforts to clarify, these lines of evidence suggest less extreme summer drying in East-Central Europe and that land-atmosphere coupling may play a key role in regulating future summer hydroclimate uncertainty in line with several recent studies (Boberg and Christensen 2012; Vogel et al. 2018; Selten et al. 2020).

On the other hand, in winter, the six SMILE mean simulations show future regional precipitation changes ranging from -0.2 to $+4.5 \%$ /decade relative to $1971-2000$ (Fig. 10a-f). For winter, the SMILEs show a similar range $(-3.7$ to $7.1 \% /$ decade) of possible future precipitation conditions in our region to both the unconstrained and the constrained CMIP5 ensemble; however, the differences between the six SMILEs are discernible (Fig. $10 \mathrm{~g})$. Unlike in summer, the top 3-ranked CMIP5 models' future winter precipitation trend values are well within $1.5 \times$ interquartile range of SMILE simulations (Fig. 10g). However, the relative role for internal variability compared with model structural differences, or the exact physical mechanism responsible for the spread in either among the different ensembles or among the members of a SMILE, remains uncertain and needs future work to untangle. For example, based on Fig. 10a-f, we note the importance of the exact geographical location of the simulated transition zone between regions with drier and wetter future conditions in the different models. This suggests that internal atmospheric circulation changes may play an important role (e.g., via regulating the extent of the northward expansion of the Hadleycell and thus the subsidence zone (Lu et al. 2007)) in determining the geographical location of the transition between projected drier and wetter conditions that might also be dependent on the amount of emitted greenhouse gases in the future (Haszpra et al. 2020b). There are plenty of rooms for future studies in these directions, which is strongly encouraged in hope of a more comprehensive understanding of future hydroclimate uncertainties.

\section{Summary and conclusions}

In this paper, we applied a ranking method to account for the possible role of structural differences between 32 CMIP5 GCMs in regulating hydroclimate projection uncertainty. The assessment of historical performance of GCM projections resulted in a constrained CMIP5 ensemble with reduced future seasonal precipitation projection spread for East-Central Europe. Moreover, the members of the constrained ensemble belong to a group of models previously identified with more realistically simulated land-atmosphere coupling (Vogel et al. 2018) and the mean of their future summer precipitation 
projections-indicating little-to-no changes $(-0.1 \% / \mathrm{de}-$ cade) - significantly differ from the unconstrained CMIP5 ensemble mean $(-3.9 \% /$ decade $)$ and from the mean of the spread of six SMILEs (-4.8\%/decade). These altogether suggest an important role for land-atmosphere coupling differences among climate models in regulating future summer hydroclimate uncertainty on top of the irreducible internal variability and calls for caution when interpreting future summer precipitation projections of the state-of-the-art SMILE simulations. We urge coordinated efforts to further quantify the relative contribution of internal variability and model structural differences in regulating future seasonal hydroclimate uncertainty in Central Europe.

Our results also shed more light on how future efforts toward reducing hydroclimate uncertainty based on regional climate models may be organized. Recent studies note that RCMs driven by GCMs with more realistic precipitation variability are more likely to have reliable precipitation projections (Syed et al. 2019). Therefore, the careful selection of driving GCMs for RCMs and the thorough evaluation of RCMs based on their landatmosphere coupling feedbacks (e.g., soil moisture-temperature/ precipitation couplings) may be a useful step toward alleviating RCM projection uncertainty, which physical constraint must also be taken into account before downscaling SMILEs to get regional ensemble simulations. In light of our results, we emphasize the possibility of less than previously thought dry summer conditions in the upcoming decades and advocate the parallel application of SMILE simulations with multi-model ensembles when producing inputs for future policymaking.

\begin{abstract}
Acknowledgments We thank Tamás Bódai and two anonymous reviewers in addition to the Editor and Ian Baxter for their insightful comments, which helped to considerably improve the paper. Authors also acknowledge the ESGF site (https://esgf.llnl.gov) and the US CLIVAR Large Ensembles Working Group in addition to the HISTALP database and the NOAA 20C Reanalysis project. We also thank for the support of the Hungarian Academy of Sciences "Lendület" program (LP2012-27/2012). This is contribution No. 68 of 2 ka Palæoclimatology Research Group.
\end{abstract}

Code availability Fortran codes of the analysis are available upon request from D.T. (topal@ucsb.edu).

Authors' contributions Z.K. provided the original idea for the paper. D.T suggested the use of large ensembles and designed the experiment with input from I.G.H. D.T processed the data, performed the calculations, created the figures, and wrote the manuscript with input from I.G.H and Z.K. All authors took part in revising the manuscript.

Funding Open access funding provided by ELKH Research Centre for Astronomy and Earth Sciences. D.T. was supported by the ÚNKP-19-3 New National Excellence Program of the Ministry for Innovation and Technology and grant NTP-NFTÖ-18 of the Ministry of Human Capacities. The work of I.G.H was supported by the János Bolyai Research Scholarship of the Hungarian Academy of Sciences.

Data availability All data is publicly available via the Earth System Grid Federation website (https://esgf-node.llnl.gov/projects/cmip5/) and the
US CLIVAR Large Ensemble archive (http://www.cesm.ucar.edu/ projects/community-projects/MMLEA/).

\section{Compliance with ethical standards}

Conflict of interest The authors declare that they have no conflict of interest.

Open Access This article is licensed under a Creative Commons Attribution 4.0 International License, which permits use, sharing, adaptation, distribution and reproduction in any medium or format, as long as you give appropriate credit to the original author(s) and the source, provide a link to the Creative Commons licence, and indicate if changes were made. The images or other third party material in this article are included in the article's Creative Commons licence, unless indicated otherwise in a credit line to the material. If material is not included in the article's Creative Commons licence and your intended use is not permitted by statutory regulation or exceeds the permitted use, you will need to obtain permission directly from the copyright holder. To view a copy of this licence, visit http://creativecommons.org/licenses/by/4.0/.

\section{References}

Ahmed K, Sachindra DA, Shahid S, Demirel MC, Chung ES (2019) Selection of multi-model ensemble of general circulation models for the simulation of precipitation and maximum and minimum temperature based on spatial assessment metrics. Hydrol Earth Syst Sci 23(11): 4803-4824. https://doi.org/10.5194/hess-23-4803-2019

Al-Yaari A, Ducharne A, Cheruy F et al (2019) Satellite-based soil moisture provides missing link between summertime precipitation and surface temperature biases in CMIP5 simulations over conterminous United States. Sci Rep 9:1657. https://doi.org/10.1038/s41598-018-38309-5

Annan JD, Hargreaves JC (2010) Reliability of the CMIP3 ensemble. Geophys Res Lett 37:L02703

Auer I, Böhm R, Jurkovic A, Lipa W, Orlik A, Potzmann R, Schöner W, Ungersböck M, Matulla C, Briffa K, Jones P, Efthymiadis D, Brunetti M, Nanni T, Maugeri M, Mercalli L, Mestre O, Moisselin JM, Begert M, Müller-Westermeier G, Kveton V, Bochnicek O, Stastny P, Lapin M, Szalai S, Szentimrey T, Cegnar T, Dolinar M, Gajic-Capka M, Zaninovic K, Majstorovic Z, Nieplova E (2007) HISTALP — historical instrumental climatological surface time series of the greater Alpine region. Int $\mathrm{J}$ Climatol 27:17-46. https://doi.org/10.1002/joc.1377

Barnes EA, Polvani LM (2015) CMIP5 projections of arctic amplification, of the North American/North Atlantic circulation, and of their relationship. J Clim 28(13):5254-5271. https://doi.org/10.1175/ JCLI-D-14-00589.1

Bartholy J, Pongrácz R (2007) Regional analysis of extreme temperature and precipitation indices for the Carpathian Basin from 1946 to 2001. Glob Planet Change 57(1-2):83-95. https://doi.org/10.1016/ j.gloplacha.2006.11.002

Baxter I, Ding Q, Schweiger A et al (2019) How tropical Pacific surface cooling contributed to accelerated sea ice melt from 2007 to 2012 as ice is thinned by anthropogenic forcing. J Clim 32(24):8583-8602. https://doi.org/10.1175/JCLI-D-18-0783.1

Beniston M, Stephenson DB, Christensen OB, Ferro CAT, Frei C, Goyette S, Halsnaes K, Holt T, Jylhä K, Koffi B, Palutikof J, Schöll R, Semmler T, Woth K (2007) Future extreme events in European climate: an exploration of regional climate model projections. Clim Chang 37:71-95. https://doi.org/10.1007/s10584-006-9226-Z

Berg A, Findell K, Lintner B, Giannini A, Seneviratne SI, van den Hurk B, Lorenz R, Pitman A, Hagemann S, Meier A, Cheruy F, Ducharne A, Malyshev S, Milly PCD (2016) Land-atmosphere feedbacks 
amplify aridity increase over land under global warming. Nat Clim Chang 6:869-874. https://doi.org/10.1038/nclimate3029

Boberg F, Christensen JH (2012) Overestimation of Mediterranean summer temperature projections due to model deficiencies. Nat Clim Chang 2:433-436. https://doi.org/10.1038/nclimate1454

Bódai T, Tél T (2012) Annual variability in a conceptual climate model: snapshot attractors, hysteresis in extreme events, and climate sensitivity. Chaos 22:023110. https://doi.org/10.1063/1.3697984

Bódai T, Drótos G, Herein M, Lunkeit F, Lucarini V (2020) The forced response of the El Niño-Southern Oscillation-Indian monsoon teleconnection in ensembles of Earth System Models. J Clim 33(6):2163-2182. https://doi.org/10.1175/jcli-d-19-0341.1

Boer GJ, Lambert SJ (2001) Second-order space-time climate difference statistics. Clim Dyn 17:213-218. https://doi.org/10.1007/ PL00013735

Brands S, Herrera S, Fernández J, Gutiérrez JM (2013) How Well Do Cmip5 Earth System Models simulate present climate conditions in Europe and Africa? Clim Dyn 41:803-817. https://doi.org/10.1007/ s00382-013-1742-8

Branstator G, Teng H (2010) Two limits of initial-value decadal predictability in a CGCM. J Clim 23(23):6292-6311. https://doi.org/10. 1175/2010JCLI3678.1

Brogli R, Kröner N, Sørland SL, Lüthi D, Schär C (2019) The role of Hadley circulation and lapse-rate changes for the future European summer climate. J Clim 32(2):385-404. https://doi.org/10.1175/ JCLI-D-18-0431.1

Cheruy F, Dufresne JL, Hourdin F, Ducharne A (2014) Role of clouds and land-atmosphere coupling in midlatitude continental summer warm biases and climate change amplification in CMIP5 simulations. Geophys Res Lett 41:6493-6500. https://doi.org/10.1002/ 2014GL061145

Christensen JH, Boberg F (2012) Temperature dependent climate projection deficiencies in CMIP5 models. Geophys Res Lett 39:L24705. https://doi.org/10.1029/2012GL053650

Compo GP, Whitaker JS, Sardeshmukh PD, Matsui N, Allan RJ, Yin X, Gleason BE, Vose RS, Rutledge G, Bessemoulin P, Brönnimann S, Brunet M, Crouthamel RI, Grant AN, Groisman PY, Jones PD, Kruk MC, Kruger AC, Marshall GJ, Maugeri M, Mok HY, Nordli $\varnothing$, Ross TF, Trigo RM, Wang XL, Woodruff SD, Worley SJ (2011) The twentieth century reanalysis project. Q J R Meteorol Soc 137:128. https://doi.org/10.1002/qj.776

Coppola E, Giorgi F, Rauscher SA, Piani C (2010) Model weighting based on mesoscale structures in precipitation and temperature in an ensemble of regional climate models. Clim Res 44:121-134. https://doi.org/10.3354/cr00940

Dai A (2006) Precipitation Characteristics in Eighteen Coupled Climate Models. J Clim 19(18):4605-4630. https://doi.org/10.1175/ JCLI3884.1

Dai A, Fyfe J, Xie S et al (2015) Decadal modulation of global surface temperature by internal climate variability. Nat Clim Chang 5:555559. https://doi.org/10.1038/nclimate2605

Dai A, Luo D, Song M, Liu J (2019) Arctic amplification is caused by sea-ice loss under increasing $\mathrm{CO}_{2}$. Nat Commun 10:121. https://doi. org/10.1038/s41467-018-07954-9

Deser C, Phillips A, Bourdette V, Teng H (2012) Uncertainty in climate change projections: the role of internal variability. Clim Dyn 38: 527-546. https://doi.org/10.1007/s00382-010-0977-x

Deser C, Lehner F, Rodgers KB, Ault T, Delworth TL, DiNezio PN, Fiore A, Frankignoul C, Fyfe JC, Horton DE, Kay JE, Knutti R, Lovenduski NS, Marotzke J, McKinnon KA, Minobe S, Randerson J, Screen JA, Simpson IR, Ting M (2020) Insights from Earth system model initialcondition large ensembles and future prospects. Nat Clim Chang 10: 277-286. https://doi.org/10.1038/s41558-020-0731-2

Ding Q, Wallace JM, Battisti DS, Steig EJ, Gallant AJE, Kim HJ, Geng L (2014) Tropical forcing of the recent rapid Arctic warming in northeastern Canada and Greenland. Nature 509:209-212. https:// doi.org/10.1038/nature13260

Ding Q, Schweiger A, L'Heureux M, Steig EJ, Battisti DS, Johnson NC, Blanchard-Wrigglesworth E, Po-Chedley S, Zhang Q, Harnos K, Bushuk M, Markle B, Baxter I (2019) Fingerprints of internal drivers of Arctic sea ice loss in observations and model simulations. Nat Geosci 12:28-33. https://doi.org/10.1038/s41561-018-0256-8

Drótos G, Bódai T, Tél T (2015) Probabilistic concepts in a changing climate: a snapshot attractor picture. J Clim 28(8):3275-3288. https://doi.org/10.1175/JCLI-D-14-00459.1

Drótos G, Bódai T, Tél T (2016) Quantifying nonergodicity in nonautonomous dissipative dynamical systems: an application to climate change. Phys Rev E 94:022214. https://doi.org/10.1103/ PhysRevE.94.022214

Drótos G, Bódai T, Tél T (2017) On the importance of the convergence to climate attractors. Eur Phys J Spec Top 226:2031-2038. https://doi. org/10.1140/epjst/e2017-70045-7

Dyer E, Washington R, Teferi Taye M (2019) Evaluating the CMIP5 ensemble in Ethiopia: creating a reduced ensemble for rainfall and temperature in Northwest Ethiopia and the Awash basin. Int $\mathrm{J}$ Climatol 40:2964-2985. https://doi.org/10.1002/joc.6377

Feng S, Fu Q (2013) Expansion of global drylands under a warming climate. Atmos Chem Phys 13:10081-10094. https://doi.org/10. 5194/acp-13-10081-2013

Garfinkel CI, Adam O, Morin E, Enzel Y, Elbaum E, Bartov M, RostkierEdelstein D, Dayan U (2020) The role of zonally averaged climate change in contributing to intermodel spread in CMIP5 predicted local precipitation changes. J Clim 33(3):1141-1154. https://doi. org/10.1175/JCLI-D-19-0232.1

Gautam J, Mascaro G (2018) Evaluation of Coupled Model Intercomparison Project Phase 5 historical simulations in the Colorado River basin. Int J Climatol 38:3861-3877. https://doi. org/10.1002/joc.5540

Gleckler PJ, Taylor KE, Doutriaux C (2008) Performance metrics for climate models. J Geophys Res 113:D06104. https://doi.org/10. 1029/2007JD008972

Harrison SP, Bartlein PJ, Izumi K, Li G, Annan J, Hargreaves J, Braconnot P, Kageyama M (2015) Evaluation of CMIP5 palaeosimulations to improve climate projections. Nature Clim Chang 5: 735-743. https://doi.org/10.1038/nclimate2649

Haszpra T, Herein M (2019) Ensemble-based analysis of the pollutant spreading intensity induced by climate change. Sci Rep 9:3896. https://doi.org/10.1038/s41598-019-40451-7

Haszpra T, Herein M, Bódai T (2020a) Investigating ENSO and its teleconnections under climate change in an ensemble view - a new perspective. Earth Syst Dynam 11:267-280. https://doi.org/ 10.5194/esd-11-267-2020

Haszpra T, Topál D, Herein M (2020b) On the time evolution of the Arctic Oscillation and related wintertime phenomena under different forcing scenarios in an ensemble approach. J Clim 33(8):31073124. https://doi.org/10.1175/JCLI-D-19-0004.1

Hawkins E, Sutton R (2009) The potential to narrow uncertainty in regional climate predictions. B Am Meteor Soc 90(8):1095-1108. https://doi.org/10.1175/2009BAMS2607.1

Hazeleger W, Severijns C, Semmler T, Ștefănescu S, Yang S, Wang X, Wyser K, Dutra E, Baldasano JM, Bintanja R, Bougeault P, Caballero R, Ekman AML, Christensen JH, van den Hurk B, Jimenez P, Jones C, Kållberg P, Koenigk T, McGrath R, Miranda P, van Noije T, Palmer T, Parodi JA, Schmith T, Selten F, Storelvmo T, Sterl A, Tapamo H, Vancoppenolle M, Viterbo P, Willén U (2010) EC-Earth. EC-Earth B Am Meteor Soc 91(10):1357-1364. https://doi.org/10.1175/2010BAMS2877.1

Herein M, Márfy J, Drótos G, Tél T (2016) Probabilistic concepts in intermediate-complexity climate models: a snapshot attractor picture. J Clim 29(1):259-272. https://doi.org/10.1175/JCLI-D-15-0353.1 
Herein M, Drótos G, Haszpra T, Márfy J, Tél T (2017) The theory of parallel climate realizations as a new framework for teleconnection analysis. Sci Rep 7:44529. https://doi.org/10.1038/srep44529

Hirschi M, Seneviratne SI, Alexandrov V, Boberg F, Boroneant C, Christensen OB, Formayer H, Orlowsky B, Stepanek P (2010) Observational evidence for soil-moisture impact on hot extremes in southeastern Europe. Nat Geosci 4:17-21. https://doi.org/10. 1038/ngeo1032

Huang J, Yu H, Guan X, Wang G, Guo R (2016) Accelerated dryland expansion under climate change. Nat Clim Chang 6:166-171. https://doi.org/10.1038/nclimate2837

Jeffrey S et al (2013) Australia's CMIP5 submission using the CSIROMk3.6 model. Aust Meteorol Oceanogr J 63:1-13. https://doi.org/ $10.22499 / 2.6301 .001$

Kay JE, Deser C, Phillips A, Mai A, Hannay C, Strand G, Arblaster JM, Bates SC, Danabasoglu G, Edwards J, Holland M, Kushner P, Lamarque JF, Lawrence D, Lindsay K, Middleton A, Munoz E, Neale R, Oleson K, Polvani L, Vertenstein M (2015) The Community Earth System Model (CESM) large ensemble project: a community resource for studying climate change in the presence of internal climate variability. B Am Meteor Soc 96(8):1333-1349. https://doi.org/10.1175/BAMS-D-13-00255.1

Kirchmeier-Young MC, Zwiers FW, Gillett NP (2017) Attribution of extreme events in Arctic Sea ice extent. J Clim 30(2):553-571. https://doi.org/10.1175/JCLI-D-16-0412.1

Knutti R (2008) Should we believe model predictions of future climate change? Philos Trans R Soc A 366:4647-4664. https://doi.org/10. 1098/rsta.2008.0169

Knutti R (2010) The end of model democracy? Clim Chang 102:395404. https://doi.org/10.1007/s10584-010-9800-2

Knutti R, Sedláček J (2013) Robustness and uncertainties in the new CMIP5 climate model projections. Nat Clim Chang 3:369-373. https://doi.org/10.1038/nclimate1716

Knutti R, Sedlacek J, Sanderson B et al (2017) A climate model projection weighting scheme accounting for performance and interdependence. Geophys Res Lett 44:1909-1918. https://doi.org/10.1002/ 2016GL072012

Kröner N, Kotlarski S, Fischer E, Lüthi D, Zubler E, Schär C (2017) Separating climate change signals into thermodynamic, lapse-rate and circulation effects: theory and application to the European summer climate. Clim Dyn 48:3425-3440. https://doi.org/10.1007/ s00382-016-3276-3

Lamarque JF, Bond TC, Eyring V, Granier C, Heil A, Klimont Z, Lee D, Liousse C, Mieville A, Owen B, Schultz MG, Shindell D, Smith SJ, Stehfest E, van Aardenne J, Cooper OR, Kainuma M, Mahowald N, McConnell JR, Naik V, Riahi K, van Vuuren DP (2010) Historical (1850-2000) gridded anthropogenic and biomass burning emissions of reactive gases and aerosols: methodology and application. Atmos Chem Phys 10:7017-7039. https://doi.org/10.5194/acp-10-7017-2010

L'Heureux M, Tippett MK, Kumar A et al (2017) Strong relations between ENSO and the Arctic Oscillation in the North American multimodel ensemble. Geophys Res Lett 44(11):654-662. https:// doi.org/10.1002/2017GL074854

Lorenz EN (1963) Deterministic Nonperiodic Flow. J Atmos Sci 20(2): 130-141. https://doi.org/10.1175/1520-0469(1963)020<0130: $\mathrm{DNF}>2.0 . \mathrm{CO} ; 2$

Lorenz R, Argüeso D, Donat MG, Pitman AJ, van den Hurk B, Berg A, Lawrence DM, Chéruy F, Ducharne A, Hagemann S, Meier A, Milly PCD, Seneviratne SI (2016) Influence of land-atmosphere feedbacks on temperature and precipitation extremes in the GLACE-CMIP5 ensemble. J Geophys Res Atmos 121:607-623. https://doi.org/10.1002/2015JD024053

Lovino MA, Müller OV, Berbery EH, Müller GV (2018) Evaluation of CMIP5 retrospective simulations of temperature and precipitation in northeastern Argentina. Int J Climatol 38:e1158-e1175. https://doi. org/10.1002/joc.5441
Lu J, Vecchi GA, Reichler T (2007) Expansion of the Hadley cell under global warming. Geophys Res Lett 34:L06805. https://doi.org/10. 1029/2006GL028443

Maher N et al (2019) The Max Planck Institute Grand Ensemble - enabling the exploration of climate system variability. J Adv Model 11:2050-2069. https://doi.org/10.1029/2019MS001639

Mann ME et al (2018) Projected changes in persistent extreme summer weather events: the role of quasi-resonant amplification. Sci Adv 4(10):eaat3272. https://doi.org/10.1126/sciadv.aat3272

McCabe GJ, Palecki MA (2006) Multidecadal climate variability of global lands and oceans. Int J Climatol 26:849-865. https://doi.org/10. 1002/joc. 1289

Merrifield AL, Brunner L, Lorenz R et al (2019) A weighting scheme to incorporate large ensembles in multi-model ensemble projections. Earth Syst Dyn Discuss (in review). https://doi.org/10.5194/esd-2019-69

Min SK, Hense A (2006) A Bayesian approach to climate model evaluation and multi-model averaging with an application to global mean surface temperatures from IPCC AR4 coupled climate models. Geophys Res Lett 33:L08708. https://doi.org/10.1029/2006GL025779

Murphy JM, Sexton DMH, Barnett DN, Jones GS, Webb MJ, Collins M, Stainforth DA (2004) Quantification of modelling uncertainties in a large ensemble of climate change simulations. Nature 430:768-772. https://doi.org/10.1038/nature02771

Nash JE, Sutcliffe JV (1970) River flow forecasting through conceptual models part I - a discussion of principles. J Hydrol 10(3):280-290. https://doi.org/10.1016/0022-1694(70)90255-6

Olson R, An S, Fan Y et al (2019) A novel method to test non-exclusive hypotheses applied to Arctic ice projections from dependent models. Nat Commun 10:3016. https://doi.org/10.1038/s41467-019-10561-x

Perez J, Menendez M, Mendez FJ, Losada IJ (2014) Evaluating the performance of CMIP3 and CMIP5 global climate models over the north-east Atlantic region. Clim Dyn 43:2663-2680. https://doi. org/10.1007/s00382-014-2078-8

Pfleiderer P, Schleussner C, Kornhuber K et al (2019) Summer weather becomes more persistent in a $2{ }^{\circ} \mathrm{C}$ world. Nat Clim Chang 9:666671. https://doi.org/10.1038/s41558-019-0555-0

Pieczka I, Pongrácz R, Szabóné André K, Kelemen FD, Bartholy J (2017) Sensitivity analysis of different parameterization schemes using RegCM4.3 for the Carpathian region. Theor Appl Climatol 130: 1175-1188. https://doi.org/10.1007/s00704-016-1941-4

Polade S, Pierce D, Cayan D et al (2015) The key role of dry days in changing regional climate and precipitation regimes. Sci Rep 4: 4364. https://doi.org/10.1038/srep04364

Reichler T, Kim J (2008) How well do coupled models simulate today's climate? B Am Meteor Soc 89(3):303-312. https://doi.org/10.1175/ BAMS-89-3-303

Rodgers KB, Lin J, Frölicher TL (2015) Emergence of multiple ocean ecosystem drivers in a large ensemble suite with an Earth system model. Biogeosciences 12:3301-3320. https://doi.org/10.5194/bg12-3301-2015

Rosenzweig C, Karoly D, Vicarelli M, Neofotis P, Wu Q, Casassa G, Menzel A, Root TL, Estrella N, Seguin B, Tryjanowski P, Liu C, Rawlins S, Imeson A (2008) Attributing physical and biological impacts to anthropogenic climate change. Nature 453:353-357. https://doi.org/10.1038/nature06937

Ruti PM, Somot S, Giorgi F, Dubois C, Flaounas E, Obermann A, Dell'Aquila A, Pisacane G, Harzallah A, Lombardi E, Ahrens B, Akhtar N, Alias A, Arsouze T, Aznar R, Bastin S, Bartholy J, Béranger K, Beuvier J, Bouffies-Cloché S, Brauch J, Cabos W, Calmanti S, Calvet JC, Carillo A, Conte D, Coppola E, Djurdjevic V, Drobinski P, Elizalde-Arellano A, Gaertner M, Galàn P, Gallardo C, Gualdi S, Goncalves M, Jorba O, Jordà G, L'Heveder B, Lebeaupin-Brossier C, Li L, Liguori G, Lionello P, Maciàs D, Nabat P, Önol B, Raikovic B, Ramage K, Sevault F, Sannino G, Struglia MV, Sanna A, Torma C, Vervatis V (2016) Med-CORDEX 
initiative for Mediterranean climate studies. B Am Meteor Soc 97(7):1187-1208. https://doi.org/10.1175/BAMS-D-14-00176.1

Sanderson BM, Knutti R, Caldwell P (2015) Addressing interdependency in a multimodel ensemble by interpolation of model properties. $\mathrm{J}$ Clim 28(13):5150-5170. https://doi.org/10.1175/JCLI-D-14-00361. 1

Santer BD et al (2018) Human influence on the seasonal cycle of tropospheric temperature. Science 361(6399):eaas8806. https://doi.org/ $10.1126 /$ science.aas 8806

Schneider T (2007) The thermal stratification of the extratropical troposphere. In: Schneider T, Sobel AH (eds) The Global Circulation of the Atmosphere. Princeton University Press, pp 47-77

Schwingshackl C, Hirschi M, Seneviratne SI (2018) A theoretical approach to assess soil moisture-climate coupling across CMIP5 and GLACE-CMIP5 experiments. Earth Syst Dynam 9:1217-1234. https://doi.org/10.5194/esd-9-1217-2018

Screen JA, Simmonds I (2010) The central role of diminishing sea ice in recent Arctic temperature amplification. Nature 464:1334-1337. https://doi.org/10.1038/nature09051

Selten FM, Bintanja R, Vautard R, van den Hurk BJJM (2020) Future continental summer warming constrained by the present-day seasonal cycle of surface hydrology. Sci Rep 10:4721. https://doi.org/10. 1038/s41598-020-61721-9

Seneviratne S, Lüthi D, Litschi M et al (2006) Land-atmosphere coupling and climate change in Europe. Nature 443:205-209. https://doi.org/ 10.1038 /nature 05095

Seneviratne SI, Wilhelm M, Stanelle T (2013) Impact of soil moistureclimate feedbacks on CMIP5 projections: First results from the GLACE-CMIP5 experiment. Geophys Res Lett 40:5212-5217. https://doi.org/10.1002/grl.50956

Senftleben D, Lauer A, Karpechko A (2020) Constraining uncertainties in CMIP5 projections of September Arctic sea ice extent with observations. J Clim 33(4):1487-1503. https://doi.org/10.1175/JCLID-19-0075.1

Sheerwood F, Fu Q (2014) A drier future? Science 343(6172):737-739. https://doi.org/10.1126/science. 1247620

Sheffield J, Barrett AP, Colle B, Nelun Fernando D, Fu R, Geil KL, Hu Q, Kinter J, Kumar S, Langenbrunner B, Lombardo K, Long LN, Maloney E, Mariotti A, Meyerson JE, Mo KC, David Neelin J, Nigam S, Pan Z, Ren T, Ruiz-Barradas A, Serra YL, Seth A, Thibeault JM, Stroeve JC, Yang Z, Yin L (2013) North American climate in CMIP5 experiments. Part I: evaluation of historical simulations of continental and regional climatology. J Clim 26(23): 9209-9245. https://doi.org/10.1175/JCLI-D-12-00592.1

Sillmann J, Kharin VV, Zhang X, Zwiers FW, Bronaugh D (2013) Climate extremes indices in the CMIP5 multimodel ensemble: part 1. Model evaluation in the present climate. J Geophys Res Atmos 118:1716-1733. https://doi.org/10.1002/jgrd.50203

Sippel S, Meinshausen N, Fischer EM, Székely E, Knutti R (2020) Climate change now detectable from any single day of weather at global scale. Nat Clim Chang 10:35-41. https://doi.org/10.1038/ s41558-019-0666-7

Slivinski LC, Compo GP, Whitaker JS, Sardeshmukh PD, Giese BS, McColl C, Allan R, Yin X, Vose R, Titchner H, Kennedy J, Spencer LJ, Ashcroft L, Brönnimann S, Brunet M, Camuffo D, Cornes R, Cram TA, Crouthamel R, Domínguez-Castro F, Freeman JE, Gergis J, Hawkins E, Jones PD, Jourdain S, Kaplan A, Kubota H, Blancq FL, Lee TC, Lorrey A, Luterbacher J, Maugeri M, Mock CJ, Moore GWK, Przybylak R, Pudmenzky C, Reason C,
Slonosky VC, Smith CA, Tinz B, Trewin B, Valente MA, Wang XL, Wilkinson C, Wood K, Wyszyński P (2019) Towards a more reliable historical reanalysis: Improvements for version 3 of the Twentieth Century Reanalysis system. Q J R Meteorol Soc 145: 2876-2908. https://doi.org/10.1002/qj.3598

Stainforth DA, Allen MR, Tredger ER, Smith LA (2007) Confidence, uncertainty and decision-support relevance in climate predictions. Phil Trans R Soc A 365:2145-2161. https://doi.org/10.1098/rsta. 2007.2074

Suh MS, Oh SG, Lee DK, Cha DH, Choi SJ, Jin CS, Hong SY (2012) Development of new ensemble methods based on the performance skills of regional climate models over South Korea. J Clim 25(20): 7067-7082. https://doi.org/10.1175/JCLI-D-11-00457.1

Swart NC, Fyfe JC, Hawkins E, Kay JE, Jahn A (2015) Influence of internal variability on Arctic sea ice trends. Nat Clim Chang 5:8689. https://doi.org/10.1038/nclimate2483

Syed FS, Latif M, Al-Maashi A et al (2019) Regional climate model RCA4 simulations of temperature and precipitation over the Arabian Peninsula: sensitivity to CORDEX domain and lateral boundary conditions. Clim Dyn 53:7045-7064. https://doi.org/10. 1007/s00382-019-04974-z

Talagrand O, Vautard R, Strauss B (1997) Evaluation of probabilistic prediction systems. Proc. ECMWF Workshop on Predictability, Reading, United Kingdom, ECMWF, 1-25, https://www.ecmwf. int/en/elibrary/12555-evaluation-probabilistic- prediction-systems

Taylor C, de Jeu R, Guichard F et al (2012a) Afternoon rain more likely over drier soils. Nature 489:423-426. https://doi.org/10.1038/ nature 11377

Taylor KE, Stouffer RJ, Meehl GA (2012b) An overview of CMIP5 and the experiment design. B Am Meteor Soc 93(4):485-498. https:// doi.org/10.1175/BAMS-D-11-00094.1

Topál D, Ding Q, Mitchell J, Baxter I, Herein M, Haszpra T, Luo R, Li Q (2020) An internal atmospheric process determining summertime Arctic sea ice melting in the next three decades: lessons learned from five large ensembles and multiple CMIP5 climate simulations. J Clim 33(17):7431-7454. https://doi.org/10.1175/JCLI-D-19-0803.1

Verfaillie D, Favier V, Gallée H, Fettweis X, Agosta C, Jomelli V (2019) Regional modeling of surface mass balance on the Cook Ice Cap, Kerguelen Islands $\left(49^{\circ} \mathrm{S}, 69^{\circ} \mathrm{E}\right)$. Clim Dyn 53:5909-5925. https:// doi.org/10.1007/s00382-019-04904-Z

Vogel MM, Zscheischler J, Seneviratne SI (2018) Varying soil moistureatmosphere feedbacks explain divergent temperature extremes and precipitation projections in central Europe. Earth Syst Dyn 9:11071125. https://doi.org/10.5194/esd-9-1107-2018

Wang C, Zhang L, Lee SK, Wu L, Mechoso CR (2014) A global perspective on CMIP5 climate model biases. Nat Clim Chang 4:201205. https://doi.org/10.1038/nclimate2118

Yapo ALM, Diawara A, Kouassi BK, Yoroba F, Sylla MB, Kouadio K, Tiémoko DT, Koné DI, Akobé EY, Yao KPAT (2020) Projected changes in extreme precipitation intensity and dry spell length in Côte d'Ivoire under future climates. Theor Appl Climatol 140: 871-889. https://doi.org/10.1007/s00704-020-03124-4

Zeng X, Pielke RA, Eykholt R (1993) Chaos theory and its applications to the atmosphere. B Am Meteor Soc 74(4):631-644. https://doi.org/ 10.1175/1520-0477(1993)074<0631:CTAIAT>2.0.CO;2

Publisher's note Springer Nature remains neutral with regard to jurisdictional claims in published maps and institutional affiliations. 